\title{
Recent Progress in Developing and Qualifying Nanostructured Ferritic Alloys for Advanced Fission and Fusion Applications
}

\author{
G.R. ODETTE ${ }^{1,2}$ \\ 1.-Departments of Mechanical Engineering and Materials, University of California Santa
} Barbara, Santa Barbara, CA, USA. 2.—e-mail: odette@engineering.ucsb.edu

This article summarizes the recent progress on developing a class of potentially transformational structural materials called nanostructured ferritic alloys, which are leading candidates for advanced fission and fusion energy applications. Here, we focus on Fe-Cr-based ferritic stainless steels containing a very high concentration of Y-Ti-O nano-oxide features that enable a host of outstanding high-temperature properties, along with unique irradiation tolerance and thermal stability. Perhaps most notably, these alloys have an unprecedented capability to manage very high helium concentrations, pertinent to fusion service, in a way that transforms this element from a severe liability to a potential asset. In addition to providing some necessary background, we update progress on: (I) the character of the nanofeatures; (II) some unifying insights on key mechanical properties; (III) a quantitative model for nanofeature coarsening; (IV) recent irradiation experiments of the effects of helium on cavity evolution and void swelling; and (V) a powerful new mechanism controlling the transport, fate, and consequences of helium.

\section{INTRODUCTION}

The success of nuclear fission and fusion as largescale sources of energy for the millennia requires new structural materials that provide and sustain a host of high-performance properties. The challenges presented by irradiation effects are particularly daunting and, in the case of fusion, are exacerbated by high quantities of helium.

The objective of this summary review is to update the status of a transformational class of iron-chromium-based ferritic stainless steels. ${ }^{1-3}$ We use the nomenclature nanostructured ferritic alloys (NFAs) to distinguish NFAs from so-called oxide-dispersionstrengthened (ODS) steels, such as PM2000, which contain a variety of coarser-scale oxides, often associated with $\mathrm{Al}$ additions. ${ }^{4}$ We also distinguish NFAs, which typically contain $14 \% \mathrm{Cr}$ (and more generally $\geq 12 \% \mathrm{Cr}$ ) along with small yttrium, titanium, and oxygen additions, from transformable ODS steels, which are alloyed with $\mathrm{C}$ and $\approx 9 \% \mathrm{Cr}$. $^{1,3}$ NFAs, which are often designated by their percentage of $\mathrm{Cr}$ content followed by YWT, as in 14YWT, have many outstanding properties. These include high tensile, creep, and fatigue strengths over a wide range of temperatures; truly remark- able thermal stability up to $1000^{\circ} \mathrm{C}$; and unmatched irradiation tolerance, especially with respect to managing high levels of helium. ${ }^{1,2,5}$ There is a large and growing worldwide interest and literature on nano-oxide dispersion-strengthened iron-based alloys that resulted in almost 150 Institute of Scientific Information Web of Science papers published in 2013 alone, as well as a focus for several special symposia and journal issues in recent years. Clearly, this article cannot provide a comprehensive list of pertinent citations; thus, these are limited to representative examples.

The outstanding characteristics of NFAs result from the interrelated presence of an ultrahigh density of Y-Ti-O rich nano-oxide features (NFs), fine grain sizes, and high dislocation densities. The NFs are multifunctional, in that they: ${ }^{1-3}$ (I) retard dislocation climb and glide thus increasing alloy strength; (II) stabilize grain and dislocation structures; and (III) act as very deep traps for helium, resulting in the formation of tiny, high-pressure gas bubbles at their interface with the matrix. ${ }^{1,2,5}$ The presence of nanometer-scale bubbles adds to the irradiation tolerance of NFAs because they act as stable sink-recombination centers that self-heal excess vacancy and selfinterstitial displacement damage defects. Indeed, the 
helium bubbles are much more effective in enhancing recombination than the oxide-matrix interface itself. $^{1,2,5}$ The bubbles are also deep traps for additional helium. Sequestering helium in bubbles reduces the accumulation of this bond-weakening element on grain boundaries, which otherwise can lead to degradation of both creep rupture and fast fracture toughness properties. ${ }^{5}$ Helium trapped in a very high number density of NF-interface small bubbles also eliminates, or greatly retards, rapid void swelling. ${ }^{1,2,5}$ Thus, NFAs may turn high helium levels from a liability to an asset.

Challenges facing NFAs include: (I) characterizing NF structures, compositions, oxide-matrix interfaces, and the various factors that control their nature; (II) determining the role NFs play in providing high strength and irradiation tolerance over a wide range of service conditions; (III) quantifying the thermal and irradiation stability of NFAs and NFs; and (IV) alloy designs, thermal-mechanical processing paths, and joining methods that create sustainable optimized NFA microstructures and yield outstanding isotropic properties and defectfree product forms. Other practical NFA challenges include corrosion and compatibility issues, reducing costs, improving alloy homogeneity and reproducibility, establishing industrial-scale supply sources, and qualifying new alloys for nuclear service. In this article we emphasize items (I) through (III). Other topics will be reviewed separately.

\section{BASIC NFA PROCESSING AND MICRO- STRUCTURES}

We focus here on Fe-14Cr-3W alloys (14YWT) microalloyed with titanium, yttrium, and oxygen solutes that are the primary constituents of the NFs. ${ }^{1-3}$ In several cases, we compare NFA properties with those of conventionally transformable 9Cr-tempered martensitic steels (TMS). However, it is worth noting that the body-centered cubic (bcc) NFAs are far superior to face-centered cubic (fcc) austenitic steels in terms of strength and, especially, irradiation tolerance.

The first NFA processing steps are typically gas atomization of prealloyed metal $14 \mathrm{Cr}-\mathrm{Fe}-\mathrm{Ti}-\mathrm{W}$ powders, followed by ball milling them with yttria $\left(\mathrm{Y}_{2} \mathrm{O}_{3}\right)$ powders. ${ }^{1-3}$ Proper milling effectively dissolves yttrium (0.1-0.3 wt\%) and oxygen (0.1-0.2 wt\%) solutes that interact with the alloy titanium (0.1$0.4 \mathrm{wt} \%)_{.}{ }^{1,3,6,7}$ The titanium, yttrium, and oxygen precipitate as NFs during hot consolidation. It is well established that titanium is needed to form small NFs, at least at higher consolidation temperatures. ${ }^{1,6,7}$ The milled powders are then canned, degassed, and consolidated by hot isostatic pressing (HIP) or hot extrusion. More recently, spark-plasma sintering has been used for consolidation. ${ }^{8} \mathrm{NF}$ precipitation kinetics are very rapid, likely partly because of the high concentration of excess defects created by ball milling. 1,6,7 However, the NF number densities $(N)$, average diameters $(\langle d\rangle)$, and size distributions depend on the alloy composition and consolidation time-temperature history. Precipitation manifests C-curve type timetemperature-transformation behavior. ${ }^{1,2,6,7}$ As the consolidation temperature drops below $1150^{\circ} \mathrm{C}$, the $\mathrm{NF}$ $N$ and volume fraction $(f)$ increase (the latter usually moderately), whereas $\langle d\rangle$ decreases. The maximum $N$ for a $3 \mathrm{~h}$ isothermal consolidation time has a C-curve nose at $\approx 675^{\circ} \mathrm{C}$, decreasing at both higher and lower processing temperatures. Consolidation is typically carried out from $850^{\circ} \mathrm{C}$ to $1150^{\circ} \mathrm{C}$, yielding $N=10^{23}$ to $10^{24} / \mathrm{m}^{3}, f=0.5$ to $1 \%$, and $\langle d\rangle \approx 1.5$ to $3.0 \mathrm{~nm}$.

As-consolidated alloys often have bimodal grain size distributions, especially at higher processing temperatures. ${ }^{1,9}$ Note that contrary to previous conclusions, however, NFs are also found in the larger grains., 9 , The smaller grains are $<1 \mu \mathrm{m}$, whereas the larger grains range up to $10 \mu \mathrm{m}$ or more. ${ }^{10,11}$ Extrusions typically have a $\langle 110\rangle$-fiber texture, with grain aspect ratios of $\approx 2$ to $10 .^{1,3,10-13}$ Dislocation densities typically range from $\approx 0.5$ to $2 \times 10^{15} / \mathrm{m}^{2} .{ }^{10,11}$ The scale of both grain and dislocation substructures is finer at lower consolidation temperatures. ${ }^{10}$ NFA consolidation is usually followed by a series of thermalmechanical processing steps needed to improve properties and fabricate product forms. ${ }^{3}$

\section{CHARACTER OF THE NFS}

A key question is, what are the compositions, structures and matrix interface orientation relationships of the NFs? Although there is a large literature on this topic, ${ }^{1-3,6,7,10,} 11,14-34$ answering this question is complicated by: (I) the typical presence of a variety of precipitate phases in NFAs over a wide range of sizes from one to hundreds of nanometers; (II) the specific characteristics of the NFs depend on several variables that differ with the alloy composition and processing path; and (III) a variety of methods have been used, and indeed are needed, to characterize the NFs, but they have all not painted the same picture. Here, we specifically define NFs as the very small Y-Ti-O oxide precipitates, in the size range of $d=1$ to $5 \mathrm{~nm}$. Atom probe tomography (APT) results have been interpreted to suggest that the NFs are highly nonstoichiometric GP zone-like transition suboxide phases, with high $\mathrm{Ti} / \mathrm{Y}$ and low $\mathrm{O} /(\mathrm{Ti}+\mathrm{Y})$ ratios, as well as high nominal iron contents. ${ }^{16-19}$ However, the magnetic-to-nuclear scattering ratios measured in small-angle neutron scattering studies are highly inconsistent with high $\mathrm{Ti} / \mathrm{Y}$ NF compositions. ${ }^{6,7,10,11}$ Most transmission electron microscopy (TEM) ${ }^{14,21-27}$ and $x$-ray diffraction (XRD) studies ${ }^{28-30}$ have found cubic fluorite $\mathrm{Y}_{2} \mathrm{Ti}_{2} \mathrm{O}_{7}(227) \mathrm{NFs}$. TEM shows NF Y/Ti ratios of $\approx 0.5$ to $1.5 . \mathrm{Y}_{2} \mathrm{TiO}_{5}$ has also been observed. ${ }^{14,15} \mathrm{TEM}$ characterization of nanometer-scale oxides extracted from commercial vendor NFA MA957 unambiguously showed that NFs are 227 oxides with $\mathrm{Y} / \mathrm{Ti} \approx 1 .{ }^{14}$ This observation is also consistent with a combined small-angle neutron scattering (SANS) and small-angle x-ray scattering (SAXS) 

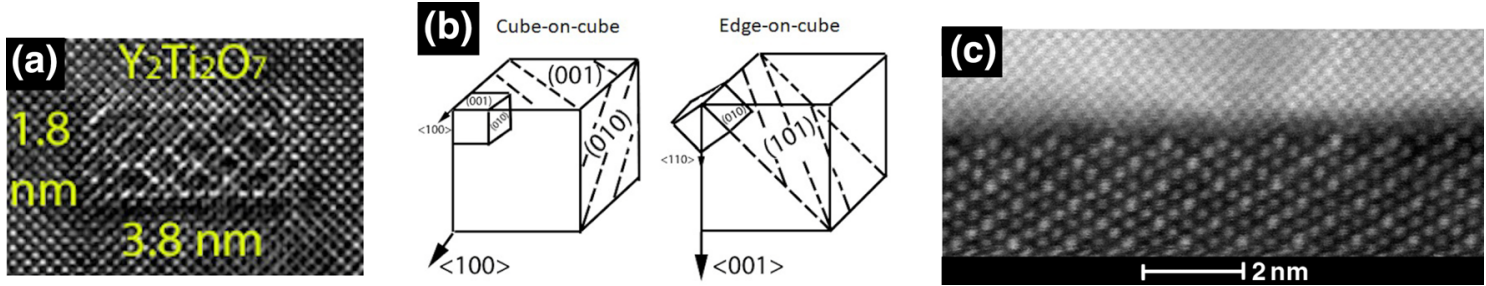

Fig. 1. (a) High-resolution TEM image of a $227 \mathrm{NF}$ in a friction-stirred MA957 weld. (b) Bulk OR observed for 227 oxides. (c) STEM image of a mesoscopic interface with a $\{100\}_{\mathrm{Fe}} \|\{110\}_{227}$ and $\langle 100\rangle_{\mathrm{Fe}} \|\langle 100\rangle_{227} \mathrm{OR}$.

characterization of $\mathrm{NFs},{ }^{31}$ as well as an anomalous SAXS measurement. ${ }^{32}$ A recent TEM study confirmed the pyrochlore structure of the $227 \mathrm{NFs}^{22}$ However, other studies have found amorphous $\mathrm{NFs},{ }^{33}$ or those having a rock salt $F m \overline{3} m^{34}$ structure, again with low Y/Ti ratios. Nevertheless, the preponderance of the evidence suggests that in most cases NFs are near stoichiometric $\mathrm{Y}_{2} \mathrm{Ti}_{2} \mathrm{O}_{7}$. Again, it is important to note that the mix of oxides that form in NFAs depends on the processing path and composition; $; 13,4,6,7,10,11,14,15,35,36$ thus, differences are not entirely unexpected.

Some of these apparent technique discrepancies might be resolved by APT and TEM observations suggesting that the NFs have an oxide core that is rich in Y-Ti-O, surrounded by a shell that is enriched in titanium. ${ }^{10,11,18-20}$ In particular, a matrix side of an interface enriched in Ti would help to rationalize the apparent differences between SANS-APT and TEM. ${ }^{10}$ Furthermore, the APT $227 \mathrm{NF}$ oxygen content may be underestimated because this interstitial element is distributed more diffusely than the substitutional yttrium and titanium solutes, ${ }^{10,11,18-20}$ therefore it is more difficult to associate with a specific oxide. The diffuse APT distribution of O is likely largely a result of surface diffusion; furthermore, some $\mathrm{O}$ may be lost in prepulse standing voltage evaporation and multiple hit events. ${ }^{20}$ The latter APT artifact may also lead to loss of some yttrium. ${ }^{10,20}$ The high nominal NF iron content in APT studies is believed to be a trajectory aberration artifact. ${ }^{10,18-20}$

The NF-matrix orientation relationship $(\mathrm{OR})$ is also of fundamental interest because this affects critical properties like interface energies, misfit strains, and local defect structures. These characteristics are important to NF interactions with point defects, helium, and dislocations. Knowing the OR is further critical to informing first-principles and atomistic interface models that are being developed. Both edge-on-cube ${ }^{25,27}$ and cube-on-cube $^{26,27}$ ORs have been reported. Figure 1a shows a high-resolution TEM image of a small pyrochlore $\mathrm{Y}_{2} \mathrm{Ti}_{2} \mathrm{O}_{7}(227) \mathrm{NF}^{25}$ The bulk OR in this case is edge-on-cube and can be described in terms of plane and direction families as $\{100\}_{\mathrm{Fe}} \mathrm{I} /\{100\}_{227}$ and $\langle 100\rangle_{\mathrm{Fe}} \mathrm{I} \mathrm{I}\langle 110\rangle_{227}$, respectively.*

*Bulk ORs list some of the parallel planes and directions between two lattices. Interfacial ORs describe the specific planes that are touching at the interface between two lattices.
Three interfacial ORs have been reported for edge-on-cube bulk ORs. ${ }^{25-28}$ An analysis of the Moire fringes shown in Fig. 1a indicates oxide-matrix misfit strains of $\approx 3 \%$ to $6 \%{ }^{25}$ Other studies have reported cube-on-cube $\{100\}_{\mathrm{F}} \mathrm{I} \mid\{100\}_{227}$ an$\mathrm{d}\langle 100\rangle_{\mathrm{Fe}} \mathrm{I} \mid\langle 100\rangle_{227}$ bulk OR, ${ }^{26,27,38}$ and in a very recent study, both types of ORs were observed. ${ }^{27}$ The bulk ORs are illustrated in Fig. $1 \mathrm{~b}$.

To better understand the oxide-metal interfaces, we are also creating mesoscopic electron-beam $\mathrm{Fe}$ deposits on oriented single-crystal $\mathrm{Y}_{2} \mathrm{Ti}_{2} \mathrm{O}_{7}$ surfaces that self-select various ORs. ${ }^{36-38}$ The deposits will be used in charged particle irradiation studies of displacement defect, helium, and hydrogen interactions with the interface and adjoining phases. Figure 1c shows a high-resolution scanning transmission electron microscopy (STEM) image of an $\mathrm{Fe}$ grain on a $\{110\} \quad \mathrm{Y}_{2} \mathrm{Ti}_{2} \mathrm{O}_{7}$ substrate along the $\langle 110\rangle \mathrm{Y}_{2} \mathrm{Ti}_{2} \mathrm{O}_{7}$ zone axis. ${ }^{38}$ The OR between the $\mathrm{Fe}$ and $\mathrm{Y}_{2} \mathrm{Ti}_{2} \mathrm{O}_{7}$ in this case is $\{100\}_{\mathrm{Fe}} \mid \mathrm{I}\{110\}_{227}$ and $\langle 100\rangle_{\mathrm{Fe}} \mid \mathrm{l}\langle 100\rangle_{227}$. The oxide-metal interface is atomically sharp. The brighter atoms in the $\mathrm{Y}_{2} \mathrm{Ti}_{2} \mathrm{O}_{7}$ side of the interface represent yttrium columns, whereas the darker atoms represent titanium columns. Oxygen cannot be detected in STEM. The slightly darker atoms in the iron side suggest that the first few layers are highly strained. Simple geometric considerations, based on CrystalMaker software, suggest that there are nominally large interface strains of $12 \%$ to $19 \%$. Note, interface vacancies in the iron may provide better lattice matching. The stoichiometry of the oxide termination surfaces has a large effect on their energies, ${ }^{39}$ and it is expected that this, along with misfit strains and structural defects, will mediate the oxidematrix interface as well.

\section{SOME RECENT OBSERVATIONS AND NEW INSIGHT ON MECHANICAL PROPERTIES}

\section{Tensile}

As shown by the examples in Fig. 2a, the roomtemperature $(\mathrm{RT})$ yield stress $\left(\sigma_{\mathrm{y}}\right)$ of NFAs at standard strain rates of $\approx 10^{-3} / \mathrm{s}$ vary over a large range from $\approx 600$ to $1600 \mathrm{MPa}{ }^{40-44}$ The former is associated with a coarse-grained fully recrystallized condition of MA95 $7^{41,57}$ whereas the latter is for an NFA extruded at $850^{\circ} \mathrm{C}$ with extremely small grains. ${ }^{43}$ Except in the highly annealed, recrystallized 

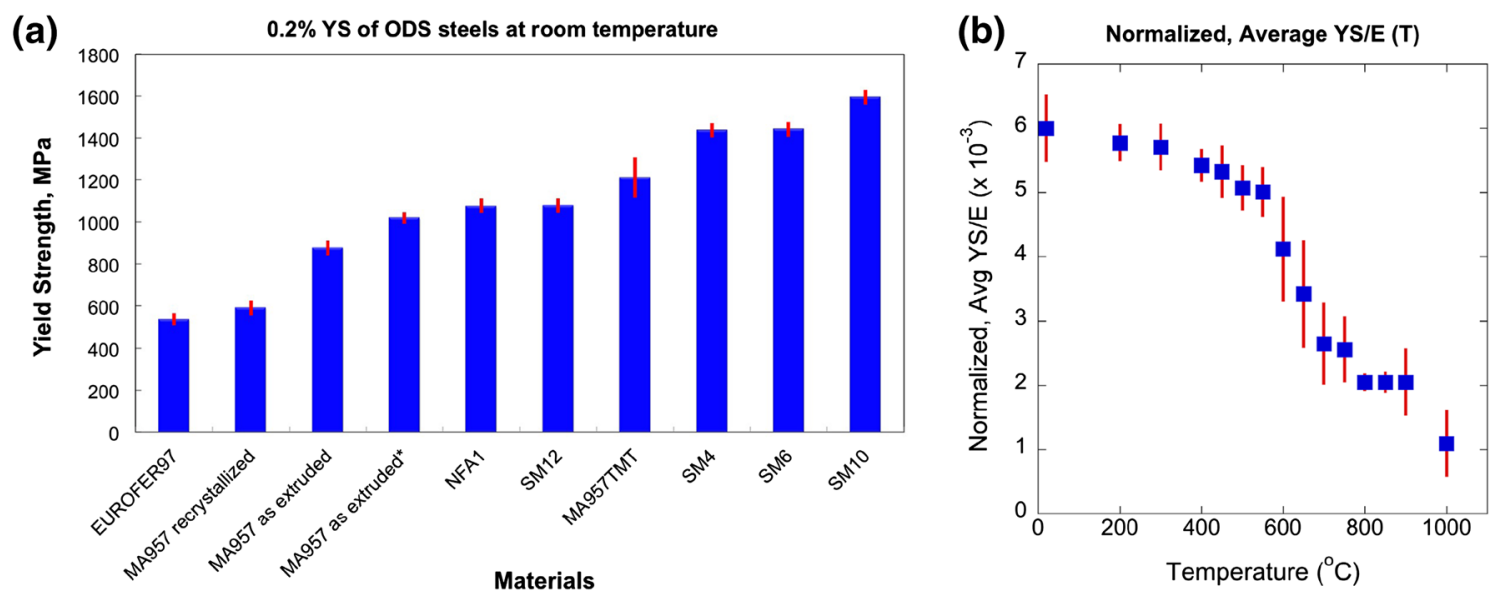

Fig. 2. (a) The yield stress (YS) of various 14YWT NFAs. (b) The temperature dependence of the average normalized yield stress of the NFAs in Fig. 2a.

condition, NFAs are much stronger than the $9 \mathrm{Cr}$ TMS Eurofer97 shown for comparison. ${ }^{45}$ Figure $2 \mathrm{~b}$ suggests a possible approximate master curve-type temperature dependence of the NFA $\sigma_{\mathrm{y}}(T)$. Here, the averages and standard deviations of $\sigma_{\mathrm{y}}(T)$ data divided by Young's modulus $(E),\left[\sigma_{\mathrm{y}} / E\right]_{n}$, for all the NFAs in Fig. 2a are shown after proportional adjustment (normalization) to a common low temperature value of $6 \times 10^{-3}$. Below approximately $400^{\circ} \mathrm{C}$, the temperature dependence of $\left[\sigma_{\mathrm{y}} / E\right]_{n}$ is relatively weak for typical static tensile test strain rate conditions $\left(\approx 10^{-3} / \mathrm{s}\right)$. Above $\approx 550^{\circ} \mathrm{C}$, there is an abrupt transition to time-dependent deformation by viscoplastic creep despite the high strain rate. At higher temperatures, the relative shape $\left[\sigma_{\mathrm{y}} / E\right]_{n}$ is consistent with power law creep from $550^{\circ} \mathrm{C}$ to $1000^{\circ} \mathrm{C}$ for an assumed activation energy of $\approx 300 \mathrm{~kJ} /$ mole and a reasonable fitted stress exponent of $\approx 12$. These results show that higher $\sigma_{\mathrm{y}}$ at lower temperature static test conditions generally translates to higher creep strength at higher temperatures. Note that the standard deviations of the normalized $\left[\sigma_{\mathrm{y}} /\right.$ $E]_{n}$ are fairly large, especially above $550^{\circ} \mathrm{C}$. In part, this occurs because of data scatter and because the average curve is not a precise representation of a particular NFA. Alloys with higher $\left[\sigma_{\mathrm{y}} / E\right]_{n}$ at a low temperature tend to have higher creep strength at a high temperature as well. Perhaps most notably, NFAs stably maintain on the order of $10-15 \%$ of their room-temperature tensile yield stress up to $\approx 2 / 3$ of the melting temperature, certainly qualifying them as a class of ferritic superalloys.

Despite their high $\sigma_{\mathrm{y}}$, however, NFAs maintain significant static ductility and strain-hardening rates. ${ }^{44,45}$ Indeed, the strain-hardening rates in NFAs significantly exceed those in 9Cr TMS. Except for highest strength NFA in Fig. 2a, SM10, the lower temperature tensile uniform strain and total elongation standard ductility measures are in the range of $\approx 2-5 \%$ and $\approx 4-25 \%$, respectively. ${ }^{44,45}$ Of course, the total elongation depends on the specimen size and geometry; however, NFA tensile ductility is also characterized by significant reductions in area. The ductile fracture mechanism, especially at lower temperatures, is primarily classic microvoid nucleation, growth, and coalescence. Microvoids typically form on Ti-oxycarbonitrides that are small but still much coarser than the NFs.

The previous tensile test results pertain to inplane loading in the longitudinal $(L)$ and transverse (T) orientations for extruded and cross-rolled plates (see Fig. 5a below). In contrast, specimens loaded in the short (S) plate thickness direction fail at lower stresses, often in the elastic region. In this case, the fracture surfaces are large flat facets separated by small ductile tearing ridges as shown in Fig. 3a. Figure $3 \mathrm{~b}$ shows the very flat macrofracture surface of a tensile specimen. Implications of fracture in the tensile S-orientation, which is essentially a delamination crack path, to fracture toughness are discussed below. Note a much earlier study of an asextruded MA957 round bar showed that the overall geometry of tensile fracture in flat dog-bone specimens also depends orientation in the following way: ${ }^{11}$ (I) shear slant ( $T$ with extrusion in gauge section thickness direction); (II) ductile cup-cone (L); and (III) flat and less locally ductile ( $T$ with extrusion in the gauge section width direction). ${ }^{12}$ This broadly mirrors the patterns observed in other NFAs.

The tensile ductility peaks in the creep regime between $600^{\circ} \mathrm{C}$ and $700^{\circ} \mathrm{C}$. This is partly caused by a high stress exponent that stabilizes the creep deformation against plastic instabilities. Coarserscale oxides also mediate creep rupture strains, which decrease above $\approx 700^{\circ} \mathrm{C}$, likely because of the lower stress exponents and more rapid growth of internal damage to form linked voids and cracks.

The high-static strength of NFAs is due to a combination of very small grain sizes (Hall-Petch) and high dislocation densities, as well as the NFs themselves. Of course, the NFs also play a critical 

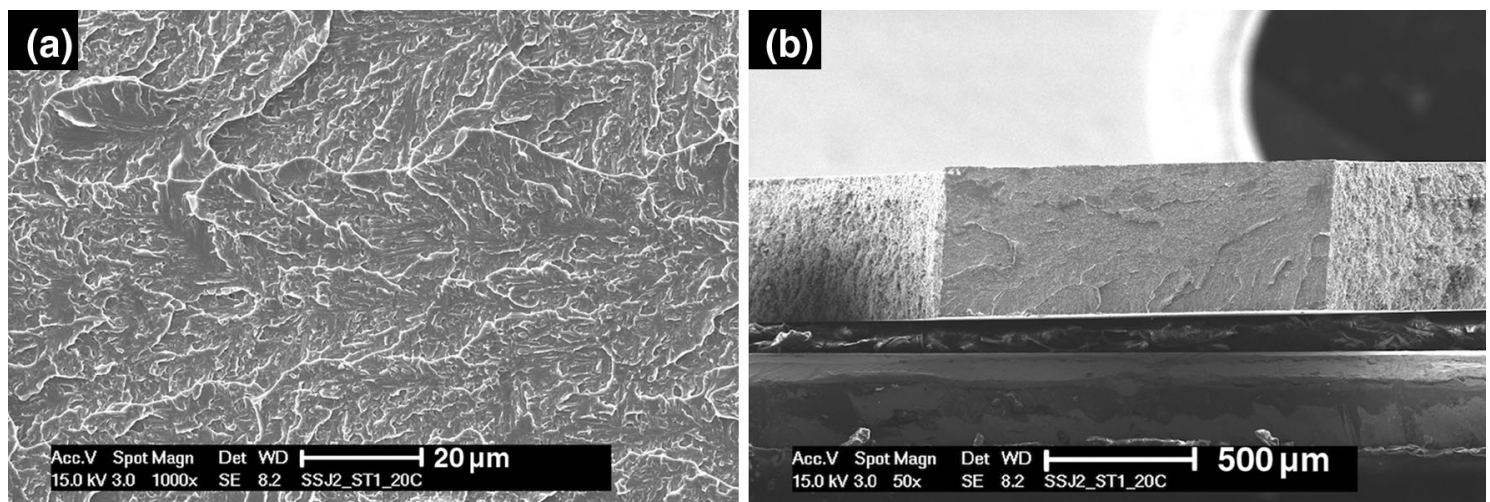

Fig. 3. (a) A scanning electron microscopy (SEM) micrograph of a fracture surface in the S orientation. (b) A SEM image of the corresponding flat macroscopic fracture surface of a tensile specimen. The corresponding $S$ and $L$ room-temperature ultimate tensile stresses were and 832 and $1253 \mathrm{MPa}$, respectively, whereas the corresponding total elongations were $0.5 \%$ and $10.6 \%$, respectively.

indirect role in stabilizing the small grains and dense dislocation structures. Earlier microstructure-property models (see Refs. ${ }^{1}$ and ${ }^{7}$ as examples) have been refined recently to better account for the various strengthening contributions in both the lower and higher temperature regimes. ${ }^{46,47}$

The major contributions to NFA strength at lower temperatures include: (I) grains/subgrains varying with the grain size $\left(d_{\mathrm{g}}\right)$ and the Hall-Petch factor $\left(k_{\mathrm{hp}}\right), \sigma_{\mathrm{hp}} \approx k_{\mathrm{hp}} / \sqrt{ } d_{\mathrm{g}}$; (II) dispersed dislocation obstacles, varying with the NF strength factor $\left[\alpha_{\mathrm{nf}}(d)\right], f$ and $\langle d\rangle, \sigma_{\mathrm{nf}} \approx 3 \alpha_{\mathrm{nf}}(d) \vee f /\langle d\rangle$; (III) dislocations varying with density $(\rho)$ and a dislocation strength factor $\left(C_{\rho}\right)$, $\sigma_{\rho} \approx C_{\rho} \sqrt{ } \rho$; and (IV) others (matrix, solid solution, and other precipitates). As an example, model-based estimates for the highest RT strength alloy shown in Fig. 1a (SM10) give net contributions of ${ }^{47,48}$ Hall-Petch $\approx 850 \mathrm{MPa}, \mathrm{NF} \approx 350 \mathrm{MPa}$, dislocations $\approx 230 \mathrm{MPa}$, and other $\approx 250 \mathrm{MPa}$. These results support a previous analysis suggesting that the NFs are not strong obstacles. ${ }^{1,7}$ Another recent study ${ }^{10,35}$ found that the NF and Hall-Petch contributions are $\sigma_{\mathrm{nf}} \approx 12,500 \sqrt{ } /\langle d\rangle$ and $\sigma_{\mathrm{hp}} \approx 10,750 / \sqrt{ } d_{\mathrm{g}} \mathrm{MPa}$, respectively, where $d$ and $d_{\mathrm{g}}$ are in nanometers. These individual strengthening contributions must be properly superimposed (added up) in a way that is bounded by linear and root-sum square addition laws (see Fig. 10). ${ }^{48}$ Furthermore, as noted previously, above a temperature that depends on the strain rate, the deformation mode increasingly transforms from primarily athermal dislocation glide to power law dislocation creep (see below). As noted above, at a high strain rate of $\approx 10^{-3} / \mathrm{s}$, the transition is complete by about $550^{\circ} \mathrm{C}$.

The qualitative, phenomenological insight on both low- and high-temperature tensile properties is useful in the following ways:

1. While some physical details and numerical parameters vary, creep at much lower strain rates and higher temperatures is controlled by a dispersed barrier-type threshold stress, and it behaves much in the same way as the high- temperature tensile test property trends. However, it is noted that some factors, such as the loading orientation, could have weaker effects at high strain rates, but are magnified in the creep regime (see below).

2. The unified tensile behavior provides insight on strengthening mechanisms and developing models of high- and low-temperature constitutive behavior.

3. This insight also provides important guidance to developing NFAs with optimized properties.

\section{Creep}

There is a large literature and corresponding models of the underlying NFA creep strengthening mechanisms (see Refs. ${ }^{1-3}$ for cross references). One example of the strength advantage is the creep rupture time for NFA MA957 tested at $800^{\circ} \mathrm{C}$ and $100 \mathrm{MPa}$ reached $38,555 \mathrm{~h},{ }^{49}$ whereas in 9Cr TMS Eurofer97, creep rupture would occur at $\approx 640^{\circ} \mathrm{C}$ for the same time and stress, based on a Larson-Miller evaluation. The corresponding stress needed to reach $1 \%$ secondary creep strain in 8 years in MA957 at $650^{\circ} \mathrm{C}$ is $\approx 200 \mathrm{MPa}$ versus $\approx 30 \mathrm{MPa}$ in the TMS alloy. Comparisons at higher temperatures are not possible because the TMS microstructures are unstable and their strength approaches very low unmeasured values. As will be described elsewhere, a larger best practice U.S. Heat of a 14YWT alloy, called FCRD NFA-1, ${ }^{44}$ has been produced with creep properties that are similar to those for some highstrength variants of MA957; there is at least one even stronger heat of a Japanese NFA, 12YWT. ${ }^{40}$

The unifying underlying physics is that strain rates are controlled by a temperature-dependent threshold power law creep stress that leads to very high nominal applied stress exponents and activation energies. ${ }^{1,40}$ The NFs and other NFA microstructures retard dislocation climb and glide, increasing the threshold stress. The coarser-scale microstructures affect creep ductility and rupture times. 


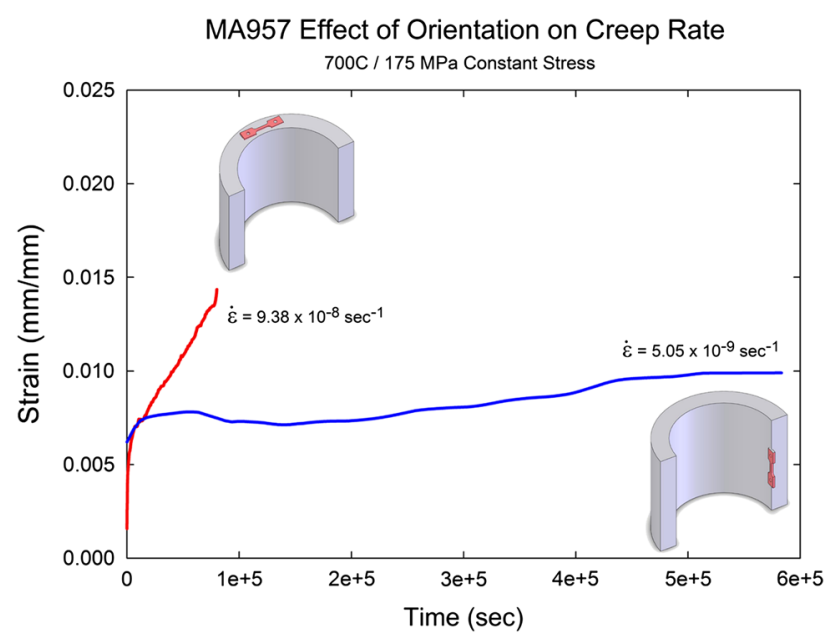

Fig. 4. Constant stress strain-time creep graph for a MA957 thickwalled tube showing higher rates and lower rupture times in the transverse versus the longitudinal orientation.

One well-known manifestation of NFA microstructural effects on creep is the highly anisotropic properties of extruded product forms. This is illustrated by the strain-time plot in Fig. 4 for an extruded NFA MA957 thick-walled tube tested at $700^{\circ} \mathrm{C}$ and $175 \mathrm{MPa}$. The transverse $(T)$ direction has much lower creep strength and rupture time compared with the axial $L$-orientation, but with a slightly higher rupture strain. Although these results are extreme, they emphasize the importance of developing processing routes that achieve more isotropic NFA microstructures and properties. ${ }^{1,3}$

Two other important points common to NFAs are illustrated in Fig. 4. First, rapid primary creep, or the initial strain upon loading, is significant and may be important in some applications. Furthermore, the transition to very rapid tertiary creep is also very rapid and is almost immediately followed by rupture. A more detailed discussion of NFA creep and creep models is beyond the scope of this article.

\section{Fracture Toughness}

In common with other bcc metals, the fracture resistance of NFAs is characterized by a toughnesstemperature curve that includes a transition from a brittle mechanism, usually cleavage, at low temperatures, to a ductile mechanism, usually microvoid coalescence, at higher temperatures. This is commonly referred to as the brittle-to-ductile transition (BDT). The BDT is typically described as a nominal temperature indexed at a specified mean toughness level (or impact energy in a Charpy test). In fact, the BDT occurs over a range of temperatures of $100^{\circ} \mathrm{C}$ or more. An elastic-plastic upper shelf toughness, which for initiation is often simply determined at the maximum load, defines fracture resistance in the higher temperature, ductile crack-tearing regime.

The fracture properties of mechanically processed NFA product forms are also typically highly anisotropic, with respect to orientations of the primary deformation directions, defined by the longitudinal and transverse deformation axis. These orientations and corresponding NFA fracture patterns are illustrated in Fig. 5a. Typically the most brittle fracture orientation is a through plate thickness crack front and longitudinal crack propagation direction (TL), directly opposite to that for creep. The effectively toughest NFA orientation is when the nominal crack plane is transverse to both the longitudinal and transverse directions; this is the short (S) thickness direction in an extruded and cross-rolled plate (LS and TS orientations). In this case, the initially in-plane cracks tend to deflect by $90^{\circ}$, as delaminations running on planes parallel to the plate faces. We hypothesize that these delaminations propagate along the boundaries of large grains and pancake-shaped powder structures that have been thinned by extrusion and cross rolling. Intermediate toughness is observed in the LT orientation.

Uniform (unimodal) fine, untextured, and equiaxed grains enhance the toughness of NFAs; conversely, even a modest fraction of large grains are believed to be detrimental. ${ }^{12}$ Perhaps the best 14YWT toughness properties obtained to date are for the NFA-1 alloy cited above. ${ }^{44}$ NFA-1 was processed by hot extrusion at a low temperature of $850^{\circ} \mathrm{C}$, followed by annealing and cross rolling at $1000^{\circ} \mathrm{C}$. This results in roughly unimodal fine grain sizes in the range of $300 \mathrm{~nm}$, and pancake-shaped layered structures formed from extruded and crossrolled consolidated powders. Figure $5 \mathrm{~b}$ shows toughness versus temperature plots for both LT and TL orientations. The corresponding load-displacement curves for the 16/3.3/1.65 (length/width/ thickness) $\mathrm{mm}$ precracked bend bars tested at $-150^{\circ} \mathrm{C}$ are shown in Fig. 5c. Remarkably, given the high $\sigma_{\mathrm{y}}$ of these alloys estimated to be $\approx 1150 \mathrm{MPa}$, fracture at $-150^{\circ} \mathrm{C}$ is still by ductile initiation and stable crack tearing. There is a transition-to-brittle cleavage only at lower temperatures, as shown by the dashed load-displacement curves at $-196^{\circ} \mathrm{C}$. The interpolated $50 \mathrm{MPa} \sqrt{ } \mathrm{m}$ indexed $\mathrm{BDT}$ are $\approx-189 \pm 5^{\circ} \mathrm{C}$ for both orientations.

The corresponding ductile tearing initiation toughness above $-100^{\circ} \mathrm{C}$ up to RT is about $95 \pm 10 \mathrm{MPa} \vee \mathrm{m}$. Although this is not a high value of upper shelf toughness per se, the required stresses at ductile fracture initiation are controlled by the alloy strength and decreased relatively slowly with subsequent stable crack tearing. The effect of tearing (crack growth) is shown by comparing the measured curves in Fig. 5c with the dashed curves derived from finite-element simulations for plane stress and strain cracked beam bending with no crack extension. Clearly, NFAs manifest a large amount of effective ductility even when they are deeply and sharply precracked. The initiation and propagation of ductile cracks is controlled by local crack tip strain associated with microvoid coalescence. Coarser scale oxides likely control the corresponding critical crack 


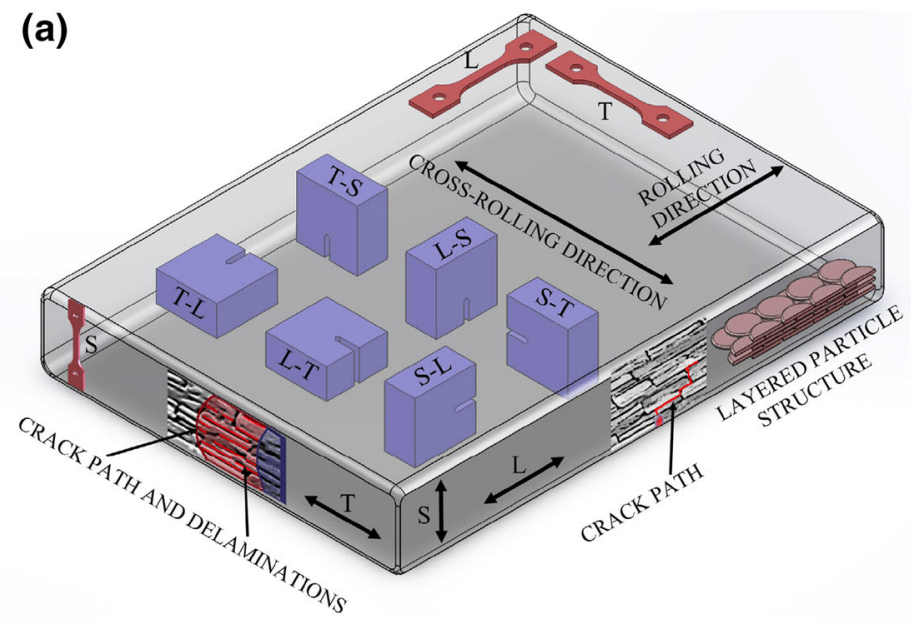

(b)

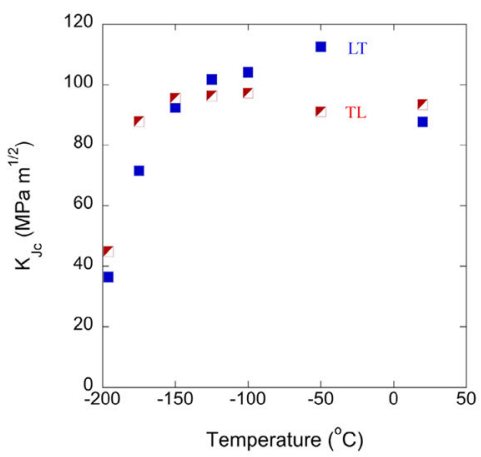

(c)

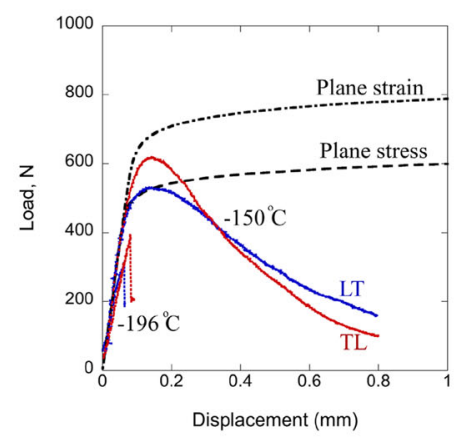

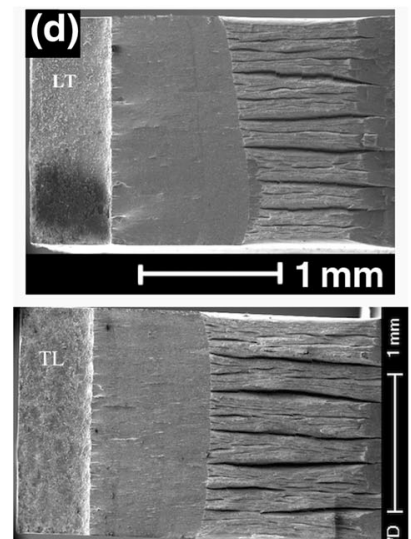

Fig. 5. (a) Orientations, layered structures, delamination, and fracture paths in extruded and cross-rolled NFA-1. (b) Toughness-temperature $K_{\mathrm{Jc}}(T)$ curves for $\mathrm{LT}$ and $\mathrm{TL}$ orientations. (c) The corresponding measured load-displacement curves at $-150^{\circ} \mathrm{C}$ and $-196^{\circ} \mathrm{C}$, along with calculated finite-element-based curves assuming no crack growth. (d) SEM images of the corresponding out-of-plane delamination cracks.

tip openings and strains. Cleaner NFAs would have higher fracture initiation strains and somewhat higher initiation loads, and lower rates. Lower rates of stress decrease with crack tearing.

The primary mechanism that gives rise to the absence of cleavage down to low temperatures is delamination between the layered pancake structures, as shown in Fig. 5d. As a consequence of delamination, deformation in the crack tip process zone transitions from a triaxial plane strain state, to a biaxial plane stress condition. This transition is accompanied by a reduction in the internal crack tip stresses by a factor of about 3 . The reduced crack tip stresses cannot reach the critical stress-stressed volume condition required for cleavage ${ }^{50}$ thus, fracture can only take place by ductile microvoid coalescence. The fact that ductile crack tearing is primarily alloy strength controlled means that toughness will decrease with increasing temperature and longer loading times. However, some ductile tearing toughness improvements can be achieved by designing cleaner alloys with reduced populations of microvoid nucleating coarser scale oxides, by optimizing the $\mathrm{Y} / \mathrm{Ti} / \mathrm{O}$ ratios.
Although the effective toughness normally decreases with increasing cracked body size, this may not be the case for NFAs because the delamination is intrinsic to the internally layered alloy microstructure; thus, the deforming crack tip units are inherently thin. In any event, it is extremely unlikely that NFAs will be used for heavy section component applications. Thus, the behavior of small test specimens is more directly transferable to relevant structures. Notably, the effective ductility provided by stable crack tearing is of great significance to actual structures that typically are associated with low-compliance primary loading and secondary thermal stress contributions. That is, the loading of the crack in the structure decreases more rapidly than that which is needed to continue crack tearing, resulting in arrest.

Finally, it is important to emphasize that whereas the delamination mechanism may produce higher toughness benefits in service, along with the high strength and anisotropic properties, ${ }^{3}$ this combination of factors results in severe deformation processing challenges. However, this topic is beyond the scope of this article. 


\section{Delamination Sites}

Figure $3 \mathrm{~b}$ shows a quasi-brittle delamination fracture surface and Fig. 5d illustrates the corresponding out-of-plane delamination cracks intersecting the fracture surface. Delaminations initially develop under the triaxial stress state conditions in the bend tests. They seem to be associated with stringers of larger grains ( $>$ to $\gg 1 \mu \mathrm{m}$ ) that are flattened in the S-direction (axis in the thickness direction). These grains are contained in even larger packets, marked by brightly imaging ductile ridges; these ridges may be prior particle boundaries of the milled powders. The powders, and their oxide scales, are deformed during extrusion and during cross rolling in the case of NFA-1.

The result is a layered pancake-type structure illustrated in Fig. 5a. The combination of oxide-rich interfaces between the powder pancakes and larger grains provide a much more brittle crack path than the surrounding fine-grained regions, both for the tensile S-tensile orientation fracture surface and the delamination planes in the TL and LT fracture toughness specimen geometries. Notably, the tensile tests of NFA-1 in the S orientation failed at ultimate stress and ductility values well below those in the $\mathrm{L}$ and $\mathrm{T}$ orientations. Although the large grain stringers and prior powder boundary effects seem to be very important, they are not well characterized or understood. Developing such insight is very important because control of these weak boundary fracture paths is critical to NFA optimization for processing as well as service.

\section{Fatigue}

The higher strength and microstructural stability of NFAs also lead to outstanding fatigue resistance. Fatigue properties are enhanced by fine grain sizes, and low inclusion contents, as well as by high strength and ductility. Figure 6, which is replotted from Ref. 51, shows the results for RT fatigue tests at a $0.7 \%$ strain amplitude for a French 14YWT NFA and a conventional 9Cr TMS Eurofer97. The NFA fatigue strength is more than 2.5 times higher than for the TMS, whereas the number of cycles to failure is 6 to 7 times lower. The key conclusions from this important work are as follows: (I) The NFA fatigue stress amplitude $\left(\sigma_{\mathrm{a}}\right)$ is nearly constant with the number of cycles $(N)$ in this case, but it decreases in the 9Cr TMS; (II) the NFA fatigue strength advantage is partly due to a smaller plastic strain component; (III) more generally, NFAs often experience cyclic strain hardening, and only shows modest softening for a few conditions, in contrast to the significant cyclic softening common to $9 \mathrm{Cr}$ TMS; (IV) NFA low-cycle fatigue lifetimes are largely governed by crack nucleation and initial growth; (V) $\sigma_{\mathrm{a}}$-failure cycle $\left(N_{\mathrm{f}}\right)$ data can be represented by alloy-specific Coffin Manson-type fits with no fatigue limit; and (VI) while NFAs have strength advantages, the plastic strain range versus $N_{\mathrm{f}}$ is below that

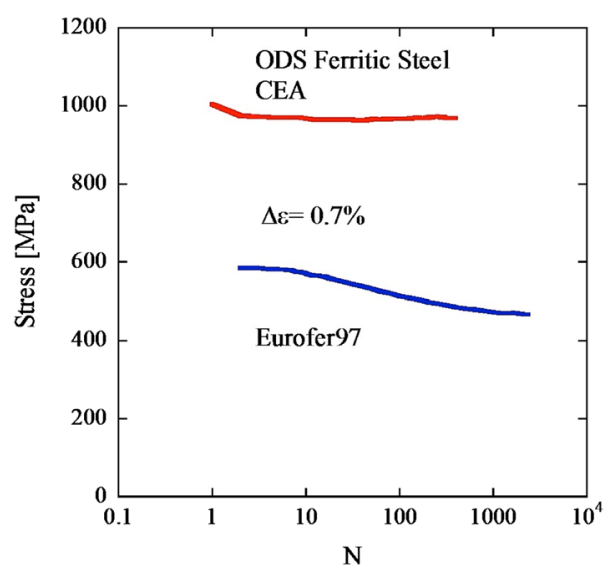

Fig. 6. Comparison of a CEA 14YWT alloy stress versus Eurofer97 stress versus fatigue cycles for a strain range of $0.7 \%$ at RT (replotted from Ref. 51).

for 9Cr TMS, indicating that they have a lower fatigue ductility.

Little data are available for NFA high-cycle fatigue or fatigue crack growth rates $[\mathrm{d} a / \mathrm{d} N(\Delta K)]$. However, because both the threshold fatigue crack growth, $\Delta K_{\mathrm{tr}}$, and especially high-cycle fatigue limits (if present) tend to increase with strength, ODS alloys should have significant advantages in these cases as well. This is also likely to be true for creepfatigue conditions. However, higher strength and low crack tip ductility may lead to faster NFA creep crack growth rates compared with TMS. Unfortunately, there is no database on these properties, nor one on the effects of many key fatigue variables, like mean stress, short cracks, cyclic frequency, variable amplitude loading, creep-fatigue hold times, and so on. Finally, the effects of the service conditions, especially the chemical environment and radiation damage, remain largely unexplored for fatigue properties.

\section{THERMAL STABILITY}

The thermal stability of the NFs is critical because coarsening may reduce their beneficial contributions to NFA function. Several thermal aging studies have been performed on various NFAs over a wide range of times and temperatures. In the most recently reported and comprehensive study, NFA MA957 was aged at temperatures between $800^{\circ} \mathrm{C}$ and $1000^{\circ} \mathrm{C}$ for up to $32.4 \mathrm{kh} .{ }^{11,52}$ No significant changes in the microhardness were observed below $900^{\circ} \mathrm{C}$ at $32.4 \mathrm{kh}$, with only modest softening at $950^{\circ} \mathrm{C} / 31.9 \mathrm{kh}$ and even at $1000^{\circ} \mathrm{C} / 21.9 \mathrm{kh}$. TEM showed that the dislocation and grain structures were stable. However, depletion of the matrix $\mathrm{Ti}$ from $\approx 0.65$ at.\% (excluding $\mathrm{NFs}$ ) before aging to 0.05 at. $\%$ after aging at $1000^{\circ} \mathrm{C}$ for $19.5 \mathrm{kh}$ was observed by APT. The matrix Ti depletion was accompanied by the growth of coarse Ti-oxides, which may have deleterious mechanical property consequences. However, this effect may be 
mitigated in newer 14YWT alloys that contain less titanium $(<0.4$ wt.\%) than MA957 $(\approx 1.0 \mathrm{wt} . \%)$.

Comprehensive SANS measurements showed that very slow $\mathrm{NF}$ coarsening occurs at both $950^{\circ} \mathrm{C}$ and $1000^{\circ} \mathrm{C}$, but not at $900^{\circ} \mathrm{C} .{ }^{11}$ Both APT and TEM measurements on MA957 aged at $1000^{\circ} \mathrm{C} / 19.5 \mathrm{kh}$ confirmed the SANS results. The APT size distributions are shown in Fig. 7a. The corresponding average TEM, SANS, and APT data in Fig. 7b show $\langle d\rangle$ increasing from $2.6 \mathrm{~nm}$ to $4.1 \mathrm{~nm}$, whereas $N$ and $f$ decrease from $4.5 \times 10^{23}$ to $1.2 \times 10^{23} \mathrm{~m}^{-3}$ and $0.60 \%$ to $0.51 \%$, respectively. APT found small decreases in the NF titanium and increases in $\mathrm{Cr}$.

These long-term, $950^{\circ} \mathrm{C}$ and $1000^{\circ} \mathrm{C}$ aging results were combined with previously reported data for aging at $1150^{\circ} \mathrm{C}$ to $1400^{\circ} \mathrm{C}$ for shorter times up to $480 \mathrm{~h}$ and were fitted using simple coarsening models: ${ }^{7,10,52}$

$$
\left[\langle d(t)\rangle^{p}-\left\langle d_{\mathrm{o}}\right\rangle^{p}\right]^{1 / p}=\left[k_{\mathrm{c}} t\right]^{1 / p}=\left[k_{\mathrm{co}} \exp \left(-Q_{\mathrm{c}} / \mathrm{R} T\right) t\right]^{1 / p}
$$

where $\left\langle d_{\mathrm{o}}\right\rangle$ is the average preaging NF diameter, $Q_{\mathrm{c}}$ is the effective activation energy for coarsening, and $p$ is the time-scaling power. The $\mathrm{p}$ is 3 for lattice diffusion-controlled growth and ranges from 2 to 5 for interface attachment and one-dimensional dislocation pipe diffusion-controlled coarsening mechanisms, respectively. The data were best fit by the $t^{1 / 5}$ model for coarsening by pipe diffusion of NF on dislocations. ${ }^{52}$ A TEM examination after long-term aging at $1000^{\circ} \mathrm{C}$ and $21.9 \mathrm{kh}$ confirmed a very strong association between NFs and dislocations, as illustrated in Fig. 7c. The least-square model fit parameters and predicted versus measured $\langle d\rangle$ standard deviations are given in Table I.

Figure 8a shows $\left[\langle d(t)\rangle^{5}-\left\langle d_{\mathrm{o}}\right\rangle^{5}\right]^{1 / 5}$ as a function of $t_{\mathrm{n}}^{1 / 5}$, where $t_{\mathrm{n}}$ is time normalized to $1200^{\circ} \mathrm{C}$. Figure $8 \mathrm{~b}$ shows the corresponding Arrhenius plot of $\ln \left(k_{\mathrm{c}}\right)$ versus $1 / T\left({ }^{\circ} \mathrm{K}\right)$ for all the temperatures. Figure $9 \mathrm{a}$ shows the predicted time needed to double the NF size as a function of temperature, which is more than 25 years at $1000^{\circ} \mathrm{C}$.

The MA957 was consolidated at around $1100^{\circ} \mathrm{C}$. It is likely that NFs formed at lower temperatures will be less stable. Figure $9 \mathrm{~b}$ shows that this is true. HIP consolidation at $850^{\circ} \mathrm{C}$ produced more $\mathrm{NFs}$ in a 14YWT model alloy than at $1150^{\circ} \mathrm{C}$. However, aging both alloys at $1200^{\circ} \mathrm{C}$ for $48 \mathrm{~h}$ reduced $N$ in both cases to nearly identical values, independent of the initial consolidation temperature.

The slow $\mathrm{NF}$ coarsening below $1000^{\circ} \mathrm{C}$ is almost entirely due to the very low solubility of yttrium in ferrite. Indeed, the measured coarsening rates are actually much faster than predicted by simple lattice diffusion models. A recent modeling study by Barnard showed that the observed coarsening is primarily due to a much greater solubility of yttrium at dislocations. ${ }^{53}$ Coupled with reasonable assumptions about yttrium pipe diffusion coefficients, NF interface energy, and oxygen potentials, the model predictions are consistent with the observed coarsening rates from $950^{\circ} \mathrm{C}$ to $1450^{\circ} \mathrm{C}$.

\section{IRRADIATION STABILITY-TOLERANCE AND NEW INSIGHTS ON HE MANAGEMENT}

The remarkable irradiation damage tolerance of NFAs has been extensively discussed in previous publications. ${ }^{1,2,5}$ In summary, this critical attribute derives from: (I) the high irradiation stability of NFAs and NFs; (II) the capability of NFAs to operate well above the displacement damage temperature

Table I. Pipe diffusion fit parameters and predicted versus measured standard deviation of $\langle\boldsymbol{d}\rangle$

\begin{tabular}{lll}
$\frac{\boldsymbol{k}_{\mathrm{co}}\left(\mathbf{n m}^{\mathbf{5}} / \mathbf{h}\right)}{4.4 \times 10^{25}}$ & $\frac{\boldsymbol{Q}_{\mathbf{c}}(\mathbf{k J} / \mathbf{m o l e})}{673}$ & $\frac{\text { SD of } \boldsymbol{p}-\boldsymbol{m}\langle\boldsymbol{d}\rangle(\mathbf{n m})}{0.67}$ \\
\hline
\end{tabular}

(a)

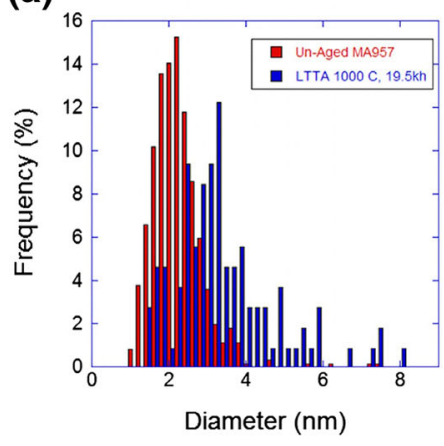

(b)

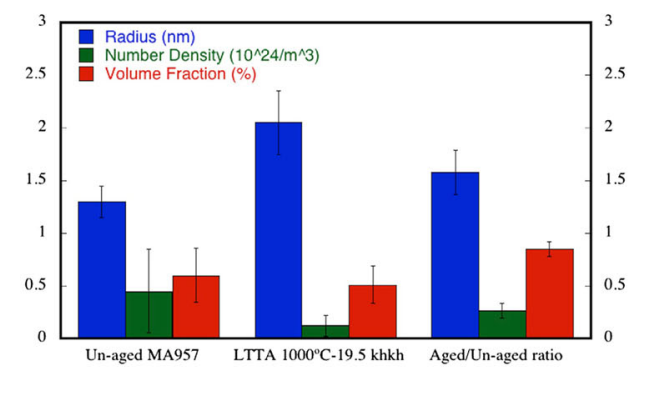

(c)

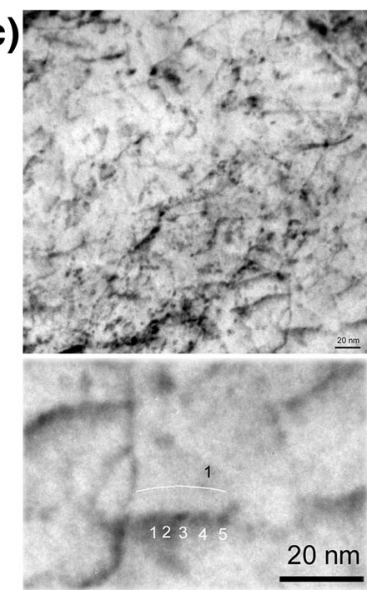

Fig. 7. As-extruded and $1000^{\circ} \mathrm{C} / 19.5 \mathrm{kh}$ aged MA957: (a) APT $\langle$ d $\rangle$ distributions; (b) TEM, SANS and APT pre- and post- aging average $\mathrm{N},\langle\mathrm{d}\rangle$ and $\mathrm{f}$ and the corresponding aged to unaged ratios; and, (c) TEM images showing strong NF association with dislocations. 

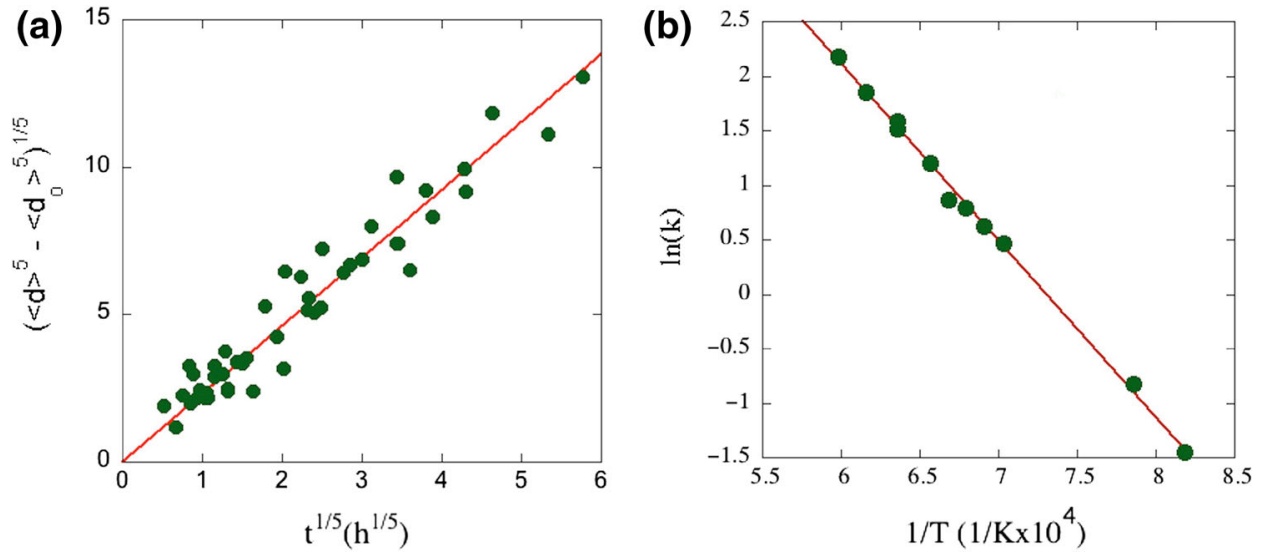

Fig. 8. (a) NF coarsening data from $950^{\circ} \mathrm{C}$ to $1450^{\circ} \mathrm{C}$ versus $t^{1 / 5}$. (b) Arrhenius plot of $\ln \left(k_{\circ}\right)$ versus $1 / T$ for all the data yielding an activation energy of $673 \mathrm{~kJ} / \mathrm{mole}$.

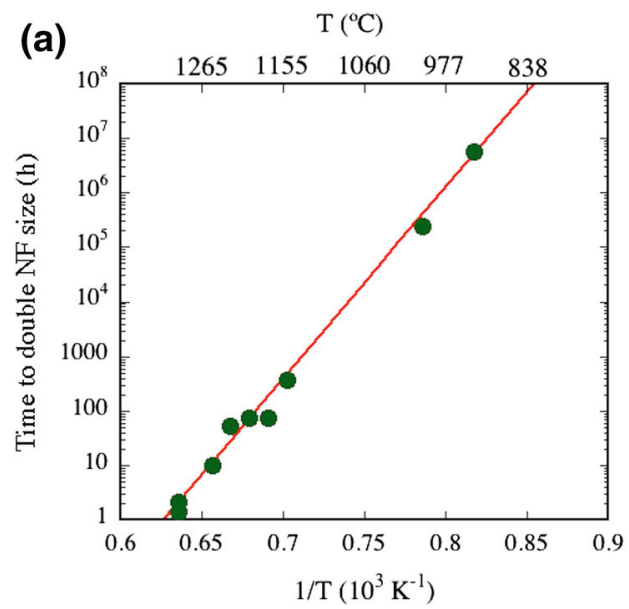

(b)

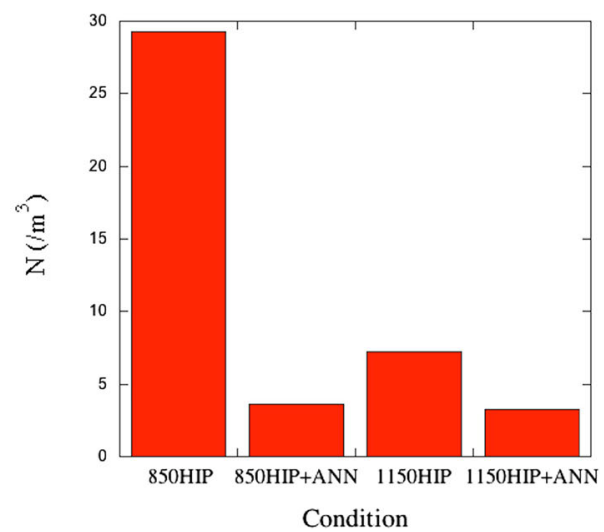

Fig. 9. (a) Time to double the NF diameter based on the fitted $p=5$ coarsening model. (b) The $N$ for HIP consolidation of a 14YWT NFA at $850^{\circ} \mathrm{C}$ and $1150^{\circ} \mathrm{C}$, and the effect of subsequent annealing at $1250^{\circ} \mathrm{C}$ for $48 \mathrm{~h}$.

regime, coupled with the potential for the $\mathrm{NF}$ to enhance point defect recombination at lower temperatures; and (III) the ability of the NF to sequester very large amounts of helium in nanometer-scale bubbles that help to protect grain boundaries, suppress void swelling, and enhance recombination.

Furthermore, unlike 9Cr TMS, NFAs retain considerable uniform strain capacity in the face of irradiation hardening. Hardening is also generally somewhat lower in NFAs. These differences are illustrated in Fig. 10: ${ }^{54}$ The TMS Eurofer97 experiences an increase in $\sigma_{\mathrm{y}}$ by $\Delta \sigma_{\mathrm{y}} \approx 392 \mathrm{MPa}$, coupled with a loss of uniform strain to $<1 \%$, following irradiation to $\approx 6 \mathrm{dpa}$ at $\approx 290^{\circ} \mathrm{C}$ : In contrast, the $\sigma_{\mathrm{y}}$ of MA957 increases by $\Delta \sigma_{\mathrm{y}} \approx 232 \mathrm{MPa}$ while retaining $\approx 6.1 \%$ uniform strain. The lower NFA irradiation hardening is in large part due to the preirradiation and post-irradiation dislocation obstacle superposition effects that, in the limit of roughly similar moderate to strong feature strengths, combine to a root sum square law. ${ }^{48}$ This lowers the net hardening contribution from the irradiationinduced features alone. The powerful effects of superposition are supported by the corresponding small $\Delta \sigma_{\mathrm{y}}$ in the very high-strength SM10 NFA of only $\approx 95 \mathrm{MPa}$. In the latter case, the uniform strains are low both before and after irradiation. The generally higher ductility in irradiated NFAs is probably mainly due to their intrinsically higher strain-hardening rates that delay plastic instabilities and necking. Higher strain hardening is, in turn, due to NFA microstructures that promote more rapid dislocation multiplication, like fine grains and cross slip or bowing around hard obstacles.

Thus, the smaller hardening in NFAs cannot be simply attributed to greater defect recombination, and this hypothetical effect, if verified, remains to be quantified. Indeed, it is notable that irradiation creep is similar in NFAs and 9Cr TMS. ${ }^{55}$ However, NFAs also experience additional hardening over a range of temperatures by $\alpha^{\prime}$ precipitation, which is accelerated by radiation-enhanced diffusion. A related recent 


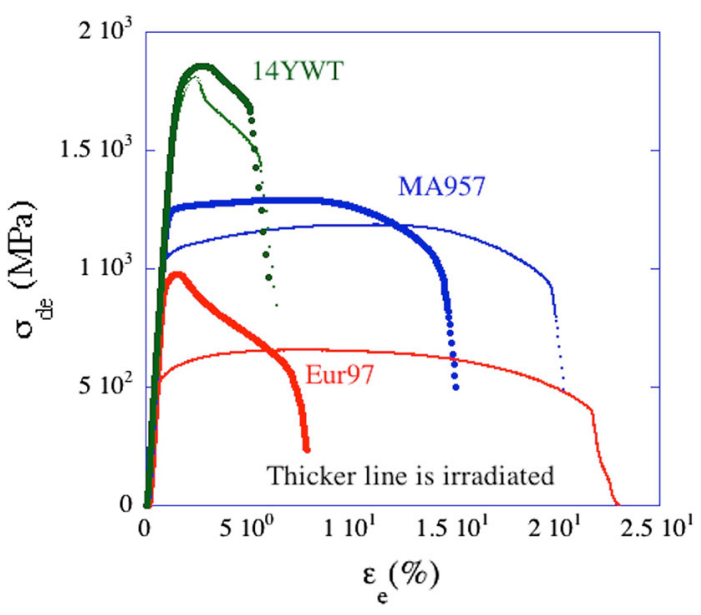

Fig. 10. Tensile engineering stress-strain curves for unirradiated and irradiated MA957, Eurofer97, and a high-strength 14YWT NFA (SM10).

development is experimental confirmation of the theoretical adjustment of the $\alpha^{\prime} \mathrm{Cr}$ solubility limit. The revised limit is lower and higher below and above $\approx 375^{\circ} \mathrm{C}$, respectively. ${ }^{56}$ The $\mathrm{Cr}$ solubility falls between $9 \%$ and $10 \%$ from $\approx 300^{\circ} \mathrm{C}$ to $475^{\circ} \mathrm{C}$, reaching $14 \%$ at $\approx 550^{\circ} \mathrm{C}$. Thus, for $14 \mathrm{YWT}$ NFA, as the temperature falls below $\approx 550^{\circ} \mathrm{C}, \alpha^{\prime}$ precipitation hardening becomes increasingly important and below $\approx 450^{\circ} \mathrm{C}$ it is highly accelerated by radiation-enhanced diffusion. The total irradiation hardening in an $\mathrm{Fe}-14 \mathrm{Cr}$ binary due to loops, Ni-Si solute clusters, and $\alpha^{\prime}$ at $290^{\circ} \mathrm{C}$ and $1.8 \mathrm{dpa}$ was found to be $\approx 450 \mathrm{MPa}$. However, the net contribution from $\alpha^{\prime}$ is estimated to be only $\approx 100 \mathrm{MPa}$.

A primary metric of the radiation tolerance of NFAs is their well-established resistance to void swelling that is discussed in detail elsewhere. .,2,5 $^{1,2}$ Void swelling occurs due to preferential annihilation of self-interstitial atom (SIA) defects at dislocation sinks, thereby leaving the excess vacancies (because SIA and vacancies are generated in equal numbers) to accumulate at growing void sinks. However, the nucleation step is difficult, and void formation predominantly occurs when helium bubbles reach a critical, unstable size and helium content. ${ }^{1,2,5}$ At a lower helium content, the bubbles are stable cavities where the gas pressure $p_{\mathrm{g}}$ is approximately balanced by the surface capillary pressure $\approx 2 \gamma / r_{\mathrm{b}}$, where $\gamma$ is the interface energy and $r_{\mathrm{b}}$ is the bubble radius. Thus, bubbles grow only with the addition of helium. Above the critical size and helium content, the cavities grow as voids, resulting in swelling. The displacements per atom (dpa) and He/dpa that are required to evolve a population of bubbles to the critical size for the onset of rapid swelling are reflected in an incubation $\mathrm{dpa}_{\mathrm{i}}$. At low helium levels, the $\mathrm{dpa}_{\mathrm{i}}$ is very high in TMS and especially in NFAs. However, higher helium and $\mathrm{He} / \mathrm{dpa}$ ratios can reduce $\mathrm{dpa}_{\mathrm{i}}$.
Figure 11a shows the dpa $\mathrm{i}_{\mathrm{i}}$ versus $\mathrm{He} / \mathrm{dpa}$ for dualion-irradiated TMS F82H at $500^{\circ} \mathrm{C}^{57-59}$ In contrast to the TMS, NFAs have very high $\mathrm{dpa}_{\mathrm{i}}$ up to extremely large helium levels. The reasons for this are discussed elsewhere in some detail., $1,2,5,57-59$ However, in summary, the NFs oxides trap and widely distribute the helium in a very high density of harmless, nanometer-scale interface bubbles that are far below the critical size. ${ }^{1,2,5}$ There is at least one bubble on each NF, and larger oxides can contain several bubbles. ${ }^{60}$ At very high He levels, individual bubbles may coalesce and ultimately may envelop the oxide. Most importantly, however, dispersing the helium to many NF bubbles prevents void formation.

Figure $11 \mathrm{~b}$ shows the dual-ion-irradiation induced volume fraction of cavities $\left(f_{\mathrm{v}}\right)$ for TMS F82H and NFA MA957 plotted on a modified dpa scale $\left(\mathrm{dpa}^{\prime}\right)$ that accounts for the effect of $\mathrm{He} / \mathrm{dpa}$ on $\mathrm{dpa}_{\mathrm{i}}$. The dose scale has been normalized at He/dpa $=30$, which corresponds to a $\mathrm{dpa}_{\mathrm{i}} \approx 40$. Thus, dpa' $=$ $\mathrm{dpa}-\mathrm{dpa}_{\mathrm{i}}(\mathrm{He} / \mathrm{dpa})+40$. The postincubation swelling in the TMS (filled symbols) occurs at a high rate in a scatter band that averages $\approx 0.1 \% / \mathrm{dpa}$. In contrast, the $f_{\mathrm{v}}$ in the NFA is low up to dpa' $\approx 140$. The nominal $f_{\mathrm{v}}$ does increase at very high dpa' and helium levels. However, TEM suggests that at very high helium levels $(>\approx 1800$ appm), the interface bubbles may coalesce and envelop the oxide. A bubble-enveloped particle images like a single cavity. However, in this case, the apparent $f_{\mathrm{v}}$ is mainly the oxide volume fraction of $\approx 0.5 \%$, as shown by the horizontal blue bar, rather than helium itself. The $f_{\mathrm{v}}$ occupied by helium is estimated to be less than $\approx 0.3 \%$ in all cases. This result is reasonably consistent with recent electron energy loss spectroscopy measurement of the helium density in small $r_{\mathrm{b}} \approx 1.3 \mathrm{~nm}$ bubbles, which is $\approx 60 / \mathrm{nm}^{3}$, or a He/ vacancy ratio of $\approx 0.6{ }^{61}$ The helium density measurements also confirm approximate predictions of an older equation of state for helium ${ }^{62}$ as well as one that was recently developed based on a new atomistic model. ${ }^{63}$

These results can be used to estimate swelling in the TMS. For example, at $\mathrm{He} / \mathrm{dpa}=10, \mathrm{dpa}_{\mathrm{i}} \approx 70$. Assuming a postincubation rate of $\approx 0.1 \% / \mathrm{dpa}$, the estimated swelling at $200 \mathrm{dpa}$ is $\approx 13 \%$. The corresponding bubble swelling in the NFA at 2000 appm helium is estimated to be less than $0.3 \%$. Note that the swelling in fcc stainless steels would be at least two orders of magnitude higher.

These dual-ion data cannot be translated to neutron irradiation conditions. However, Fig. 11b also includes data from in situ helium injection (ISHI) irradiations at $500^{\circ} \mathrm{C}$, performed in a high-flux isotope reactor at neutron-relevant conditions, shown as the large crosshatched symbols. Details of the ISHI technique are given elsewhere. ${ }^{5}$ Briefly, $\mathrm{Ni}$ (or $\mathrm{B}$ or $\mathrm{Li}$ )-bearing implanter layers are used to inject high-energy $\alpha$-particles into an adjacent material that is simultaneously undergoing fast neutron-induced displacement damage. Based on an estimated 

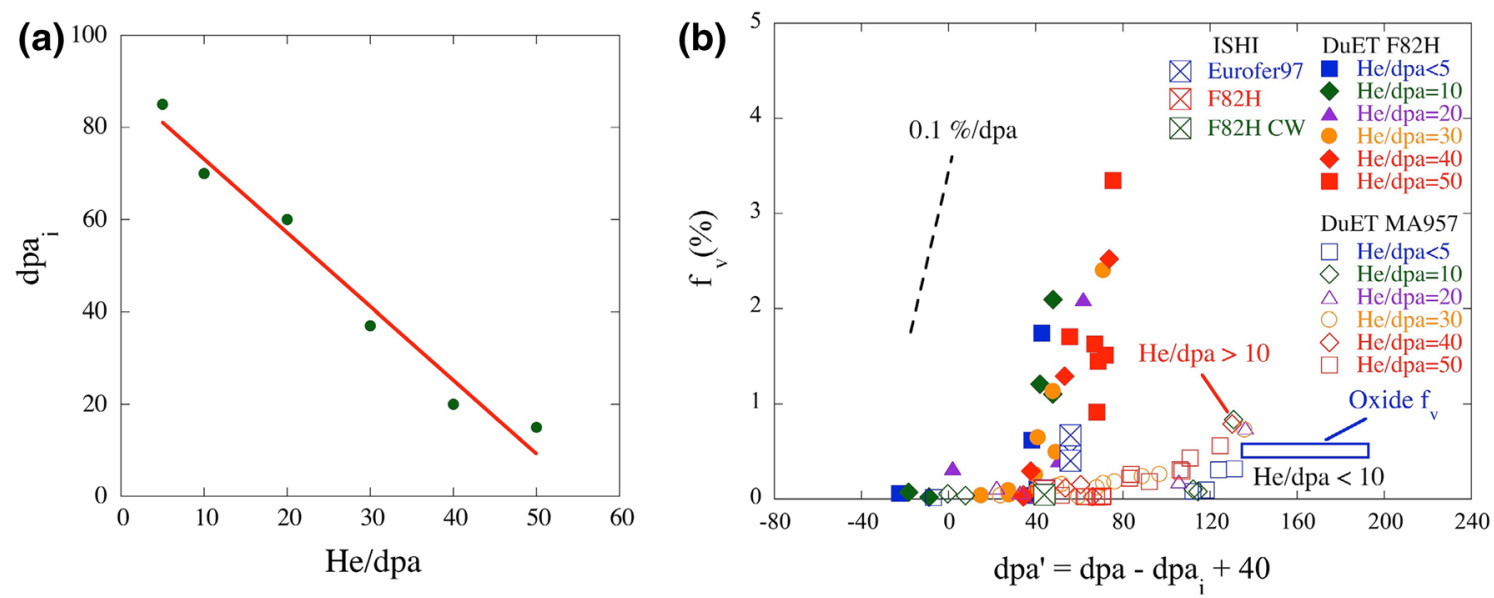

Fig. 11. (a) The incubation $\mathrm{dpa}_{\mathrm{i}}$ for void swelling as a function of $\mathrm{He} / \mathrm{dpa}$ for $500^{\circ} \mathrm{C}$ dual-ion irradiations of TMS F82H and NFA MA957. (b) The corresponding cavity volume fraction $f_{\mathrm{v}}$ as a function of the adjusted $\mathrm{dpa}^{\prime}$.

neutron ISHI incubation $\mathrm{dpa}_{\mathrm{i}} \approx 5 \mathrm{dpa}$ at $\mathrm{He} /$ $\mathrm{dpa} \approx 50$, the limited ISHI $f_{\mathrm{v}}$ data fall in the trend band for the dual-ion irradiation. The ISHI database will soon be extended from 21 to $\approx 35 \mathrm{dpa}$. If the lower trends persist for the TMS, then this dpa increment extrapolates to a more significant $f_{\mathrm{v}} \approx 1.9 \%$ swelling.

Finally, we note new insight regarding the behavior of helium in NFAs that likely has a very profound impact on irradiation tolerance. This relates to first-principles calculations that show deep helium trapping in 227 oxide octahedral interstitial sites. ${ }^{64}$ The corresponding oxide solution energy $\left(E_{\mathrm{o}}\right)$ is only $\approx 0.94 \mathrm{eV}$ compared with that in a Fe-Cr matrix substitutional site $\left(E_{\mathrm{m}}\right)$ of $\approx 2.34 \mathrm{eV}$, yielding a binding energy of $\approx 1.5 \mathrm{eV}{ }^{64}$ A 227 oxide volume fraction of the only $0.5 \%$ is capable of storing thousands of appm helium. Thus, essentially all the helium generated in NFAs at lower dpa may be initially trapped in the 227 oxides.

Although this hypothesis seems to be at odds with $\mathrm{nm}$-scale helium bubbles on the NF interface, these observations are actually fully consistent with one another. ${ }^{64}$ Helium first partitions from the matrix into an oxide (or its interface) where it remains trapped until a sufficiently large interface bubble, $r_{\mathrm{b}}>r_{\mathrm{c}}$, forms, where $r_{\mathrm{c}}$ is a critical oxide-attached bubble radius. This occurs when the corresponding helium energy in bubble $\left(E_{\mathrm{b}}\right)$ is lower than in the oxide at $E_{\mathrm{o}}$. The $E_{\mathrm{b}}$ has contributions from the pressurized helium itself and the curved bubble interface, with $E_{\mathrm{b}} \approx 4 \gamma / r_{\mathrm{b}}$, where $\gamma$ is the matrix interface energy. Thus, at $r_{\mathrm{b}}>r_{\mathrm{c}}$ and $E_{\mathrm{b}}<E_{\mathrm{o}}$, helium subsequently flows from the oxide into the attached bubble, which grows by absorbing vacancies up to an equilibrium size that is controlled by the number of gas atoms it contains. This mechanism suggests that the size of the bubble or bubbles is strongly affected by the total helium in the oxide. That is, larger oxides lead to larger bubbles. Although detailed physics of bubble nucleation is complex, this does not alter the ultimate fate of helium, which is to reside in interface bubbles.

Despite its ultimate fate, however, transient helium trapping in the oxides is not an unimportant detail for several reasons. First, bubble formation does not have to rely on relatively weak helium atom trapping at the oxide-matrix interface. Once formed, bubbles are the primary sinks for collecting additional helium. Another important implication is that whereas fine nanometer-scale oxides help to distribute helium in very small interface bubbles up to high temperatures, lower numbers of larger oxides, individually containing more helium, may actually promote swelling by forming interface bubbles that quickly convert to growing voids. Figure 12 illustrates some of the concepts discussed above including the presence of large voids on coarser scale oxides in a PM2000 (or 14YW) alloy. ${ }^{65}$

\section{Modeling}

Detailed discussions of several recent advances in modeling various aspects of the fundamental character of NF and NFA processing and functionality are beyond the scope of this article. Progress has been substantial; however, we elaborate on the recent thermokinetic modeling applied to long-term thermal aging cited above. ${ }^{53}$ The aging research is part of a larger effort to model NF nucleation, growth, and coarsening, as well as the corresponding effects of both (I) composition and processing variables and (II) service time-temperature variables. This research also treats the effects of titanium, $\mathrm{Ti} / \mathrm{Y}$ ratios (at.\%), and $\mathrm{O}$ activity on oxide phase selection and oxide precipitate $N,\langle d\rangle$, and $f$. Figure 13 (redrawn from Ref. 53) shows a calculated oxide phase selection diagram for the $\mathrm{Fe}-\mathrm{O}-\mathrm{Y}-\mathrm{Ti}$ system at $1000^{\circ} \mathrm{C}$. The oxides that form depend on the $\mathrm{Ti} /(\mathrm{Y}+\mathrm{Ti})$ ratio and the $\mathrm{O}$ activity (represented in terms of partial pressure). Increasing $\mathrm{O}$ activity stabilizes the titanium-containing complex oxides 
(a)

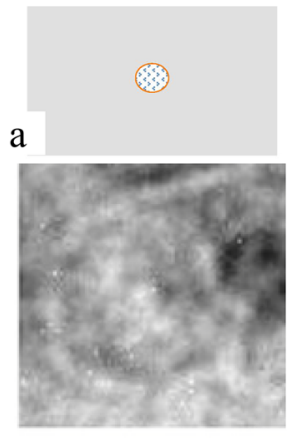

$5 \mathrm{~nm}$ (b)
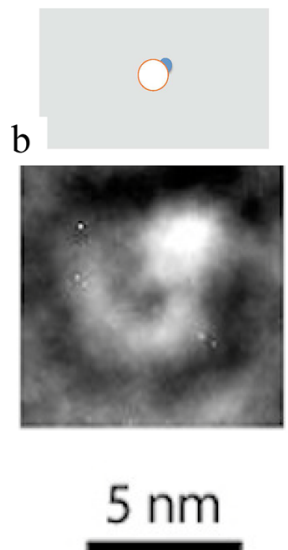

(c)

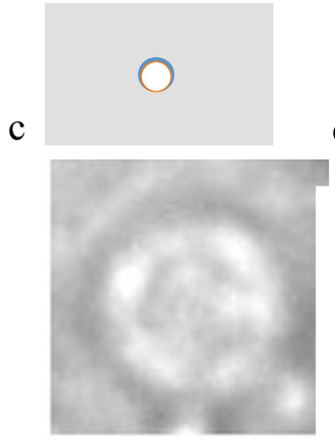

$10 \mathrm{~nm}$ (d)

d
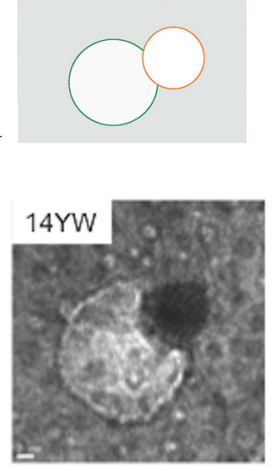

$10 \mathrm{~nm}$

Fig. 12. (a) Illustrations of an oxide containing helium. (b) An oxide with an attached helium bubble. (c) An oxide surrounded by a helium bubble or bubbles. (d) A larger oxide that nucleates a growing void. Schematic illustrations are on the top and TEM examples of these oxide-cavity arrangements are shown on the bottom.

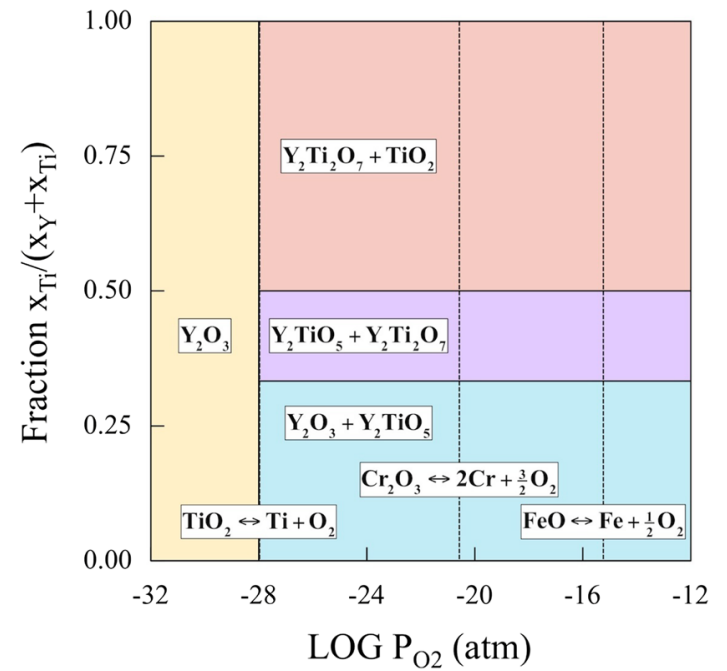

Fig. 13. A phase diagram for $\mathrm{Y}-\mathrm{Ti}-\mathrm{O}$ oxides in an iron matrix showing the effects of the activity of oxygen, expressed in terms of the $\mathrm{O}_{2}$ partial pressure, and the $\mathrm{Ti} /(\mathrm{Y}+\mathrm{Ti})$ ratio (redrawn from Ref. 53).

relative to $\mathrm{Y}_{2} \mathrm{O}_{3}$. At low $\mathrm{Y} /(\mathrm{Y}+\mathrm{Ti})$ ratios, the oxides include $\mathrm{Y}_{2} \mathrm{O}_{3}$ and $\mathrm{Y}_{2} \mathrm{TiO}_{5}$. There is a sweat spot at intermediate values of $\mathrm{Y} /(\mathrm{Y}+\mathrm{Ti})$ for the formation of 227 as the primary oxide phase. At high $\mathrm{Ti} /$ $(\mathrm{Y}+\mathrm{Ti})$ and $\mathrm{O}$ activity, $\mathrm{TiO}_{2}$ forms along with the 227 oxide. Thus, the thermodynamic model can be used to optimize NFA designs by controlling Ti, Y, and $\mathrm{O}$ compositions to maximize $227 \mathrm{NF}$ formation while avoiding large quantities of unwanted $\mathrm{TiO}_{2}$.

\section{SUMMARY, SOME CLOSING REMARKS, AND FUTURE RESEARCH}

The objective of this article is to provide a brief background on NFAs and to update progress on some, but certainly not all, NFA topics since our last
$J O M$ publication in $2010 .^{2}$ In summary, we make the following conclusions:

- While some discrepancies remain, the character of the NFs, as predominantly near stoichiometric $\mathrm{Y}_{2} \mathrm{Ti}_{2} \mathrm{O}_{7}$ pyrochlore, has been more clearly demonstrated and the reasons for apparent differences are somewhat better understood. The next steps include rigorous modeling and experimentally probing the functionality of the oxides and oxide-matrix interfaces.

- There has been significant progress on expanding the mechanical property database for NFAs. This includes a better understanding and modeling of deformation and tensile (macro defect free) fracture over a wide range of strain rates and temperatures in both the static and time-dependent regimes. Deformation processes manifest a useful degree of commonality and overlapping mechanisms that lead to a wide range of yield and creep strengths that can be microstructurally understood. Mitigating anisotropic properties in extruded and deformed NFAs without severely compromising their performance sustaining microstructures and properties remains a major challenge $^{3}$ that was not addressed in this article.

- Progress has been made on improving the fracture resistance of NFAs, although we did not attempt to capture all the recent literature on this topic. We focused here on exploiting delamination mechanisms in achieving fracture by ductile crack tearing down to very low test temperatures in extrusions consolidated at relatively low temperatures and cross rolled that produce fine-grained microstructures. The resulting high in-plane (LT and TL) nearly isotropic tearing toughness is controlled by the alloy strength even in sharply cracked bodies that manifest large effective ductility and defect tolerance. Significant progress has also been made on developing a fatigue 
database and characterizing plastic strain-controlled processes that lead to superior fatigue strength in NFAs compared with TMS. The next steps include additional measurements of ductiletearing toughness, fatigue and creep crack growth, and creep fatigue at higher temperatures. Another imperative is to explore optimizing properties by improving alloy purity and O-Ti-Y balances as well as exploring and controlling the role of powder particle oxide scales and large grain delamination sites.

- A large database has been used to develop a quantitative model of NF coarsening and NFA stability over temperatures from $900^{\circ} \mathrm{C}$ to $1450^{\circ} \mathrm{C}$. The best-fit model is based on a dislocation pipe diffusion mechanism, which was further confirmed by TEM observations. The fitted activation energy is also reasonably consistent with first-principles modeling of enhanced yttrium solubility at dislocations and classic pipe diffusion kinetics. The results show that NFs will be highly stable up to $1000^{\circ} \mathrm{C}$, with corresponding size doubling times in excess of $2 \times 10^{5} \mathrm{~h}$. The $\mathrm{NF}$ coarsening model is for a commercial vendor NFA, MA957, consolidated at a high temperature. Preliminary data suggest that the NFs in alloys consolidated at lower temperatures will be less stable. Thus, long-term aging experiments must be extended to a much wider range of NFAs with both composition and processing path variants.

- There seems to be little remaining question that $\mathrm{NFs}$ are stable under neutron irradiation conditions and that fine-scale oxides can manage helium up to very high levels. The effectiveness of NFAs in suppressing other forms of radiation damage over a wide range of conditions, especially at lower temperatures in the displacement damage dominated regime, as well as at ultrahigh dpa, up to 400 or more, remains to be established and quantified. Characterization of existing neutron-irradiated alloys that have yet to be examined is the highest priority. Additional carefully designed charged-particle-irradiation studies that are integrated with, and complementary to, the neutron-irradiation database development are needed to help inform physically based microstructural and property evolution models that are required to qualify NFAs for nuclear service.

- The possible role of oxides in deeply trapping and storing helium prior to the formation of interface bubbles represents very important new insight. Experimental verification of such trapping, measuring, and modeling associated helium interface bubble formation are important next-step objectives. Furthermore, these new mechanisms must be incorporated in master models of helium and defect generation, transport, fate, and consequence.

- While only noted here in passing, the treatment of the thermodynamics of phase selection and the corresponding thermokinetics of NF nucleation, growth, and coarsening represent critical advances. However, this is only one of many more examples of modeling opportunities used to guide the design of optimized NFAs as well as in developing robust tools and a knowledge base to predict microstructural and property evolutions during processing and long-term service.

This update did not attempt to cover all the recent progress on NFAs and other nano-oxide dispersionstrengthened alloys of major interest. In particular, we did not cover key issues related to processing, fabricating, and joining challenging product forms, like thin-walled tubing. Furthermore, we did not address many other outstanding practical issues like cost and an industrial supply base. As we have stated previously, NFAs are still in the early stages of development. However, they represent a transformational material system, especially for advanced nuclear energy applications, much in the same way that nickel-based superalloy single-crystal turbine blades represented a transformational revolution in jet engine and gas turbine technology.

\section{ACKNOWLEDGEMENTS}

Except for the sections on fatigue and some of the TEM, the work described in this article was primarily carried out at the University of California Santa Barbara (UCSB), in many cases also involving our valued external collaborators. Thus, the author gratefully acknowledges the numerous outstanding scientists who conducted the research that include: $\mathrm{Y}$. Wu (UCSB), J. Cisten (LBNL), and P. Hosemann (UC Berkeley)-TEM studies; Md. Ershadul Alam, D. Gragg, and K. Fields (UCSB)—deformation and fracture measurements and observations; N.J. Cunningham and M.J. Alinger (UCSB)—SANS, APT, longterm thermal aging experiments and predictive coarsening modeling; T. Yamamoto (UCSB) and our Kyoto University collaborators-dual-ion irradiations; R. Kurtz, D. Edwards, and B. Yao (PNNL)-ISHI TEM; S. Maloy (LANL) and D. Hoelzer (ORNL)-NFA development including NFA-1; Y. Jiang (South Central University China)-first-principles modeling of helium trapping in oxides; and L. Barnard and D. Morgan (University of Wisconsin)—thermokinetic modeling of NF nucleation growth and coarsening. We further note that Drs. Wu, Cunningham, and Yamamoto have played key crosscutting roles within our broad research thrust on NFAs. The tensile data in Fig. 10 were obtained as part of an ATR National Scientific User Facility irradiation at Idaho National Laboratory with postirradiation testing carried out at LANL led by T. Saleh and S. Maloy. The research at UCSB was supported by the U.S. Department of Energy Office of Fusion Energy Sciences (DE-FG03-94ER54275) and the Office of Nuclear Energy university programs administered by INL (IDNL Award \#00119430 8-442520-59048).

\section{REFERENCES}

1. G.R. Odette, M.J. Alinger, and B.D. Wirth, Ann. Rev. Mater. Res. 38, 471 (2008).

2. G.R. Odette and D.T. Hoelzer, JOM 62 (1), 84 (2010). 
3. S. Ukai, Comprehensive Nuclear Materials (Atlanta, GA: Elsevier, 2012).

4. A. Kimura, R. Kasada, N. Iwata, H. Kishimoto, C.H. Zhang, J. Isselin, P. Dou, J.H. Lee, N. Muthukumar, T. Okuda, M. Inoue, S. Ukai, S. Ohnuki, T. Fujisawa, and T.F. Abe, J. Nucl. Mater. 417, 176 (2011).

5. Y. Dai, G.R. Odette, and T. Yamamoto, Comprehensive Nuclear Materials (Atlanta, GA: Elsevier, 2012).

6. M.J. Alinger, G.R. Odette, and D.T. Hoelzer, Acta Mater. 57, $392(2009)$

7. M.J. Alinger (Ph.D. dissertation, University of California Santa Barbara, 2004).

8. X. Boulnat, D. Fabregue, M. Perez, M.H. Mathon, and Y. de Carlan, Metall. Mater. Trans. A 44-6, 2461 (2013).

9. C.C. Eiselt, M. Klimenkov, R. Lindau, and A. Moeslang, J. Nucl. Mater. 386-388, 525 (2009).

10. N.J. Cunningham (Ph.D. dissertation, University of California Santa Barbara, 2012).

11. N.J. Cunningham, Y. Wu, D. Klingensmith, and G.R. Odette, Mater. Sci. Eng. A, 613, 296 (2014).

12. M.J. Alinger, G.R. Odette, and G.E. Lucas, J. Nucl. Mater. 307-311, 484 (2002).

13. P. Miao, G.R. Odette, T. Yamamoto, M. Alinger, D. Hoelzer, and D. Gragg, J. Nucl. Mater. 367-370, 208 (2007).

14. Y. Wu, E.M. Haney, N.J. Cunningham, and G.R. Odette, Acta Mater. 60, 3456 (2012).

15. D. Bhattacharyya, P. Dickerson, G.R. Odette, S.A. Maloy, A. Misra, and M.A. Nastasi, Philos. Mag. 92, 2089 (2012).

16. M.K. Miller, E.A. Kenik, K.F. Russell, L. Heatherly, D.T. Hoelzer, and P.J. Maziasz, Mater. Sci. Eng. A 353, 140 (2003).

17. M.K. Miller, D.T. Hoelzer, E.A. Kenik, and K.F. Russell, J. Nucl. Mater. 329-333, 338 (2003).

18. E.A. Marquis, Appl. Phys. Lett. 93, 181904 (2008).

19. C.A. Williams, E.A. Marquis, A. Cerezo, and G.D.W. Smith, J. Nucl. Mater. 400, 37 (2010).

20. P. Wells, N.J. Cunningham, and G.R. Odette, Fus. Mater. Semiann. Prog. Rep. (2012).

21. S. Yamashita, S. Ohtsuka, N. Akasaka, S. Ukai, and S. Ohnuki, Philos. Mag. Lett. 84, 525 (2004).

22. R. Kasada, N. Toda, K. Yutani, H.S. Cho, H. Kishimoto, and A. Kimura, J. Nucl. Mater. 367-370, 222 (2007).

23. H. Sakasegawa, L. Chaffron, F. Legendre, L. Boulanger, T. Cozzika, M. Brocq, and Y. de Carlan, J. Nucl. Mater. 384, 115 (2009).

24. M. Klimiankou, R. Lindau, and A. Möslang, J. Nucl. Mater. 329, 347 (2004)

25. J. Ciston, Y. Wu, G.R. Odette, and P. Hosemann, Microsc. Microanal. 18, 760 (2012).

26. J. Ribis and Y. de Carlan, Acta Mater. 60, 238 (2012).

27. K. Dawson and G.J. Tatlock, J. Nucl. Mater. 444, 252 (2014).

28. J.R. Rieken, I.E. Anderson, M.J. Kramer, G.R. Odette, E. Stergar, and E. Haney, J. Nucl. Mater. 428, 65 (2012).

29. T. Okuda and M. Fujiwara, Mater. Sci. Lett. 14, 160 (1995).

30. H. Sakasegawa, M. Tamura, S. Ohtsuka, S. Ukai, H. Tanigawa, A. Kohyama, and M. Fujiwara, J. Alloy Compd. 452, 2 (2006)

31. M. Ohnuma, J. Suzuki, S. Ohtsuka, S.W. Kim, T. Kaito, M. Inoue, and H. Kitazawa, Acta Mater. 57, 5571 (2009).

32. M. Dumont, L. Commin, I. Morfin, F. DeGeuser, F. Legendre, and P. Maugis, Mater. Charact. 87, 138 (2014).

33. M.C. Brandes, L. Kovarik, M.K. Miller, and M.J. Mills, J. Mater. Sci. 47, 3913 (2012).

34. A. Hirata, T. Fujita, C.T. Liu, and M.W. Chen, Acta Mater. 60,5686 (2012).
35. N.J. Cunningham, Y. Wu, A. Etienne, E.M. Haney, G.R. Odette, E. Stergar, D.T. Hoelzer, Y.D. Kim, B.D. Wirth, and S.A. Maloy, J. Nucl. Mater. 444, 35 (2014).

36. S. Ukai and S. Ohtsuka, Energy Mater. 2, 26 (2007).

37. T. Stan, Y. Wu, G.R. Odette, K.E. Sickafus, H.A. Dabkowska, and B.D. Gaulin, Metall. Mater. Trans. A 44, 4505 (2013).

38. T. Stan, S. Kramer, Y. Wu, and G.R. Odette, Fus. Mater. Semiann. Prog. Rep. (2015).

39. L. Yang, Y. Jiang, G.R. Odette, W. Zhou, Z. Liu, and Y. Liu, Acta Mater. 61, 7260 (2013).

40. M.C. Salston and G.R. Odette, Trans. ANS 1148 (2008).

41. A. Alamo, V. Lambard, X. Averty, and M.H. Mathon, J. Nucl. Mater. 329, 333 (2004).

42. M.L. Hamilton, D.S. Gelles, R.J. Lobsinger, G.D. Johnson, W.F. Brown, M.M. Paxton, R.J. Puigh, C.R. Eiholzer, C. Martinez, and M.A. Blotter, Fabrication Technological Development of the Oxide Dispersion Strengthened Alloy MA957 I for Fast Reactor Applications, PNL-13168 (Richland, WA: Pacific Northwest Laboratory, 2000).

43. D. Hoelzer, Personal Communication, ORNL, 2014.

44. M.E. Alam, N.J. Cunningham, D. Gragg, K. Fields, G.R. Odette, D.T. Hoelzer, and S.A. Malloy, Fus. Mater. Semiann. Prog. Rep. (2014).

45. M. Rieth, M. Schirra, A. Falkenstein, P. Graf, S. Heger, H. Kempe, R. Lindau, and H. Zimmermann, Forsch. Karls. FZKA6911 (2003).

46. J.H. Kim, T.S. Byun, D.T. Hoelzer, S. Kim, and B.H. Lee, Mater. Sci. Eng. A 559, 101 (2013)

47. J.H. Kim, T.S. Byun, D.T. Hoelzer, C.H. Park, J.T. Yeom, and J.K. Hong, Mater. Sci. Eng. A 559, 111 (2013).

48. G.R. Odette and G.E. Lucas, Rad. Eff. Defect. Solid. 144, 189 (1998).

49. D. Hoelzer, J.P. Shingledecker, R.L. Klueh, M.K. Miller, and J. Bentley, Fus. Mater. Semiann. Prog. Rep. (2008).

50. W.J. Yang, G.R. Odette, T. Yamamoto, P. Milao, M.J. Alinger, M. Hribernik, and J.H. Lee, J. Nucl. Mater. 155, 616 (2007).

51. I. Kubena, B. Fournier, and T. Kruml, J. Nucl. Mater. 424, $101(2012)$

52. N.J. Cunningham, M.J. Alinger, G.R. Odette, and D. Klingensmith, Fus. Mater. Semiann. Prog. Rep. (2012).

53. L. Barnard (Ph.D. dissertation, University of Wisconsin, 2013).

54. T. Saleh and S. Maloy, Personal Communication, LANL, 2014.

55. M.B. Toloczko, F.A. Garner, and S.A. Maloy, J. Nucl. Mater. 428, 170 (2012).

56. M. Bachhav, G.R. Odette, and E.A. Marquis, Scripta Mater. 74, 48 (2014)

57. T. Yamamoto, Y. Wu, G.R. Odette, K. Yabuuchi, S. Kondo, and A. Kimura, J. Nucl. Mater. 449, 190 (2014).

58. T. Yamamoto, Y. Wu, G.R. Odette, S. Kondo, and A. Kimura, Fus. Mater. Semiann. Prog. Rep. (2014).

59. G.R. Odette, T. Yamamoto, and Y. Wu, Fus. Mater. Semiann. Prog. Rep. (2015).

60. Y. Wu, T. Yamamoto, N. Cunningham, G.R. Odette, S. Kondo, and A. Kimura, Fus. Mater. Semiann. Prog. Rep. (2013).

61. Y. Wu, G.R. Odette, T. Yamamoto, and P. Hosemann, Fus. Mater. Semiann. Prog. Rep. (2013).

62. R.E. Stoller and G.R. Odette, J. Nucl. Mater. 131, 118 (1985).

63. R.E. Stoller and Y.N. Osetskiy, Fus. Mater. Semiann. Prog. Rep. (2014).

64. L. Yang, Y. Jiang, G.R. Odette, T. Yamamoto, Z. Liu, and Y. Liu, J. Appl. Phys. 115, 143508 (2014).

65. B. Yao, D.J. Edwards, R.J. Kurtz, G.R. Odette, and T. Yamamoto, Fus. Mater. Semiann. Prog. Rep. (2012). 